\title{
Performance of Industrial-Type Cladding Materials
}

Gerald A. Sleater

Center for Building Technology Institute for Applied Technology National Bureau of Standards

Washington, D. C. 20234

March 1973

Final report describing work performed from June 1969 through May 1972.

Prepared for

Office of the Chief of Engineers, U. S. Army

Directorate of Civil Engineering, U. S. Air Force

Naval Facilities Engineering Command, U. S. Navy 



\section{PERFORMANCE OF INDUSTRIAL-TYPE}

\section{CLADDING MATERIALS}

Gerald A. Sleater

Center for Building Technology Institute for Applied Technology

Not for publiation National Bureau of Standards

Washington, D. C. 20234

March 1973

Final report describing work performed from June 1969 through May 1972.

\section{Prepared for}

Office of the Chief of Engineers, U. S. Army

Directorate of Civil Engineering, U. S. Air Force

Naval Facilities Engineering Command, U. S. Navy

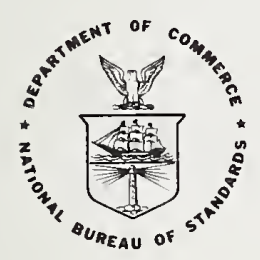

U. S. DEPARTMENT OF COMMERCE, Frederick B. Dent, Secretary 



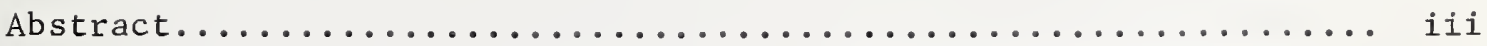

S. I. Conversion Units.......................... iv

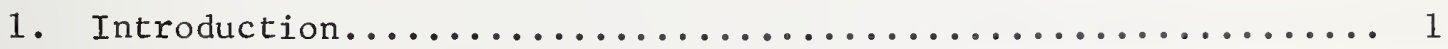

1.1 Sponsorship............................. 1

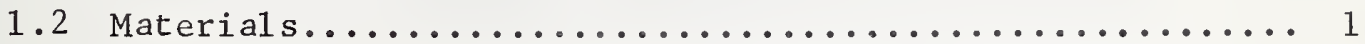

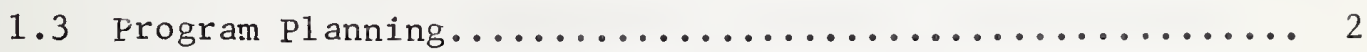

1.4 Program Goal.............................. 3

2. Recommended Performance Specification for Industrial

Cladding Systems........................... 4

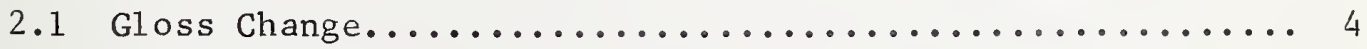

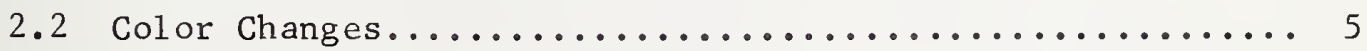

2.3 Impact Resistance......................... 5

2.4 Abrasion Resistance........................6 6

2.5 Salt Spray Resistance.................... 7

2.6 Moisture Resistance....................... 7

3. Acknowledgment............................. 8

Appendix A. Laboratory Test Program...................... A-1

A.1 Scope of Laboratory Testing................... A-1

A.2 Applied Coating Continuity................... A-1

A.3 Resistance to Impact......................... A-2 


\section{INDEX (continued)}

Page Number

A.4 Abrasion Resistance.......................... A-3

A.5 Salt Spray Resistance........................ A-4

A.6 Accelerated Weathering........................ A-5

A.7 Moisture Resistance........................... A-6

Appendix B. Natura1 Weathering Exposure Program.............. B-1

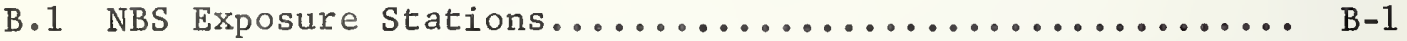

B.2 Specimen Mounting and Evaluation in Natural Weathering

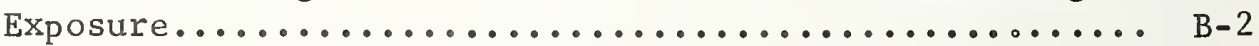

B.3 Specific Instances of Degradation from Natural

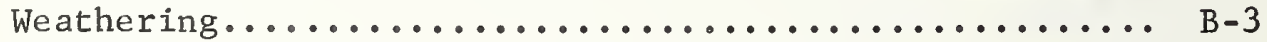

Appendix C. Field Inspection Tours of In-Service Cladding........ C-1

C.1 Inspection Areas and Procedure.................. C-1

C.2 Cladding Failures Observed...................... C-2

Appendix D. Correlation of Accelerated and Natural. Weathering

Test Results................................... D-1

D.1 Limitation of Correlation Between the Two Test Methods................................... D-1

D.2 Qualitative Correlation....................... D-1

Appendix E. Recommendations for Prevention of In-Service Damage to $\mathrm{Cl}$ adding. ................................... E-1

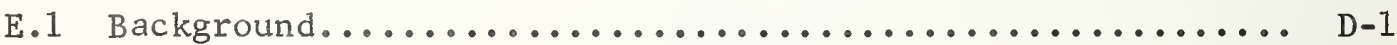

E.2 Instances of Observed Damage and Recommendations for Its Prevention.............................. E-1

Appendix F. Figures................................. F-1 


\section{AB STRACT}

The main objective of a three year research program in industrial-type cladding systems at the National Bureau of Standards was to develop a performance specification for such cladding materials. The research program consisted of 1 aboratory and natural weathering tests of cladding specimens, complemented by field inspection of in-service industrial cladding. Only cladding with an aluminum or a galvanized steel substrate, covered with a factory-applied organic coating, was evaluated.

The 1 aboratory testing program included measurement of color and gloss changes consequent to accelerated weathering procedures, and tests for cladding resistance to salt spray, moisture permeation, impact and abrasion. Exposure of cladding specimens to natural weathering was done at seven National Bureau of Standards exposure stations throughout the United States. Field inspection tours of in-service cladding were made in the Eastern and Southeastern United States and Puerto Rico.

The criteria to implement the performance specification for industrial cladding were based upon the combined information from test data and field inspection. In addition, the results of cladding exposure to natural weathering were correlated with the test data from cladding exposure to 1 aboratory accelerated weathering procedures. Suggestions for protection of cladding from in-service damage are also given.

\section{KEYWORDS}

Industrial cladding; organic coatings; accelerated weathering; natural weathering; field inspection; performance specification 


\section{SI Conversion Units}

The measurement units used throughout this report conform to the terminology of the test methods that were employed. In keeping with the stated policy of the National Bureau of Standards to facilitate use of the International Systems of Units (SI), the following 1 ist of conversion factors* is included to assist those readers who may wish to convert the units used in this report to SI units.

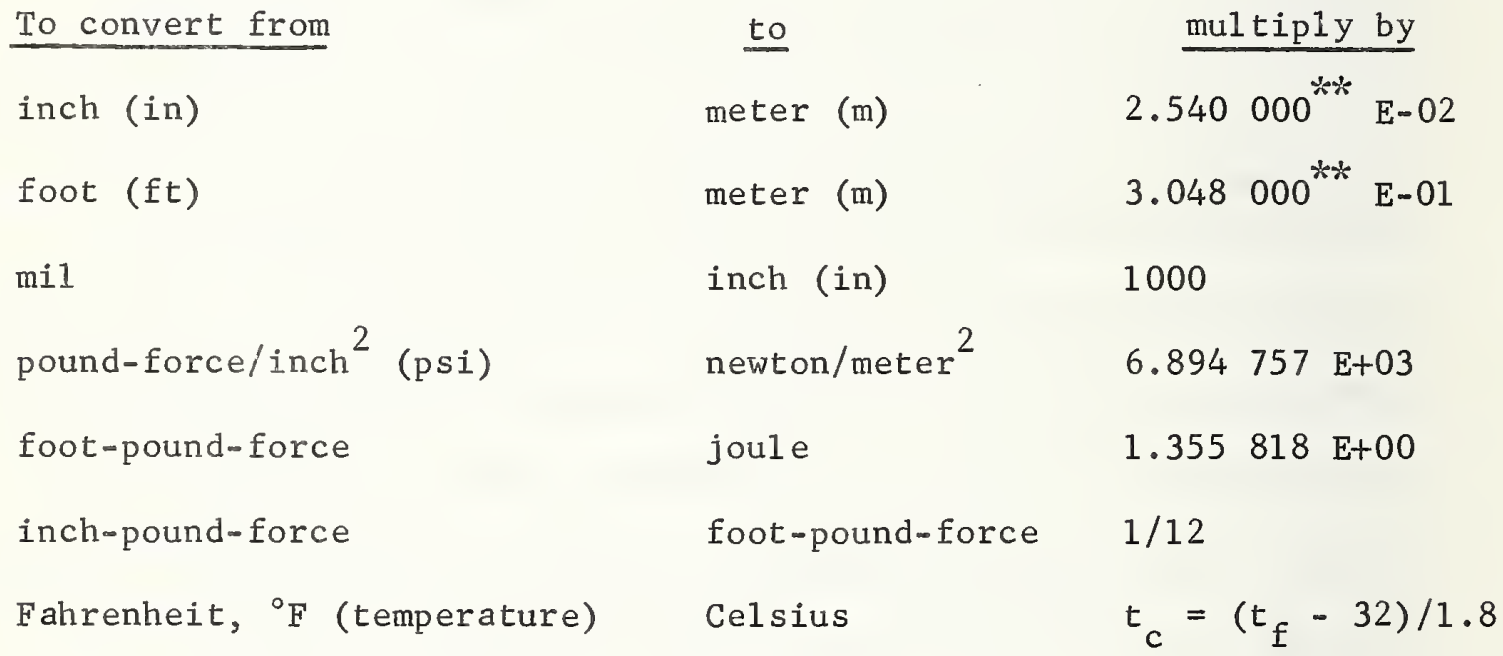

* ASTM Metric Practice Guide, NBS Handbook 102, available from the U. S. Government Printing Office, Washington, D. C. 20402 (40 cents).

A double asterisk ( $*$ ) after the sixth decimal place indicates that the conversion factor is exact and that all subsequent digits are zero. 


\section{INTRODUCTION}

\subsection{Sponsorship}

The Center for Building Technology, NBS, was requested by the Tri-Service Building Materials Investigational Committee* to initiate a research program that would obtain 1 aboratory and natural weathering data relevant to the performance of industrial-type cladding systems.

The test data obtained through such a research program would have a threefold purpose. First, it would be useful in evaluating and selecting short-term test methods that would assist in projecting the long-term in-service durability of industrial cladding systems. Both criteria and test methods could be combined in a performance specification for industrial cladding systems. Third, to determine what correlations, if any, existed between the results from laboratory accelerated weathering and those from natural weathering exposure.

\subsection{Materials}

The research program was to evaluate only cladding, roll formed, and with a metallic substrate (either aluminum or galvanized steel) covered with some form.of factory-applied organic coating system. The cladding materials were representative of the 1969-1970 industrial cladding line.

*This Committee is composed of representatives of the Army, Navy, and Air Force. 
Any cladding system included in this program could be classified in one of three categories:

1. Liquid Process Coating: One or more films of synthetic resin coating material applied as a 1 iquid to the substrate, then heat cured. The 1 iquid coatings included fluoropolymer, siliconized polyester, acrylic, vinyl, siliconized acrylic, and alkyd types for evaluation.

2. Dry Film Laminate: A dry film coating material bonded to the metal substrate with an adhesive.

3. Protected Metal: A galvanized steel substrate coated with a relatively thick coating of an asphaltic material, with or without an inert mineral addition, which is in turn covered with a thin decorative coating.

\subsection{Program Planning}

In developing a research program to meet the objectives of the sponsoring agency, previous unpublished work done on residential siding materials was used as a guide. However, fundamental differences between residential siding and industrial cladding precluded including in a study of industrial cladding methodology appropriate to the evaluation of residential siding.

For example, in testing industrial cladding with a metal substrate, there was no need to investigate swelling of the substrate, as was done for wood backed residential siding. Also, the low glosses, inclusion of dark colors, and varying surface textures among the specimens of industrial cladding hindered testing for appearance and maintainability comparable to that done for residential siding. 
The research program that was followed used a twofold approach of laboratory and natural exposure testing to evaluate the factors affecting industrial cladding performance. The laboratory tests were Federal Standard Test Methods or ASTM Test Standards*. Natural exposure testing made use of seven NBS exposure stations. Additional information, as to in-service durability, was obtained through the inspection of structures incorporating cladding systems similar to those systems evaluated through the 1 aboratory and natural weathering test procedures.

\subsection{Program Goal}

The main goal of the test programs and field inspection tours was accomplished through preparation of a recommended performance specification for industrial cladding systems. This performance specification lists those properties or conditions that an industrial cladding system should maintain or fulfill in long-term use. Listed for each property or condition are the criterion or criteria that define the respective functional limits, together with the short-term test methods that would indicate cladding conformance to the stated criterion or criteria.

*Activities outside the Federal Government may obtain copies of Federal Standards as outlined under General Information in the Index of Federal Specifications and Standards and at prices indicated in the Index. The Index, which includes cumulative monthly supplements as issued, is for sale on a subscription basis by the Superintendent of Documents, U. S. Government Printing Office, Washington, D. C. 20402. Federal Government Activities may obtain copies of Federal Standards from established distri:bution points in their agencies.

American Society for Testing and Materials (ASTM) Standards may be obtained by applying to the American Society for Testing and Materials, 1916 Race Street, Philadelphia, Pennsylvania 19103. 
The recommended performance specification comprises the remainder of the report. The test information upon which the performance specification was based is presented in a series of appendices. The results of the laboratory test program, the natural weathering exposure, and the field inspection tours are given in separate appendices. In two additional appendices, the correlation of the results of accelerated and natural weathering procedures, and a series of recommendations intended to prevent in-service damage to cladding is outlined.

\section{RECOMMENDED PERFORMANCE SPECIFICATION FOR INDUSTRIAL CLADDING SYSTEMS}

\subsection{Gloss Change}

Requirement: The decorative coating shall maintain a uniform, acceptable appearance under the effects of environmental weathering.

Criterion: The coating shall not show a change of more than $50 \%$ from the original gloss after 1000 hours of accelerated weathering.

Test 1: Federa1 Test Method, 141a, 6142, Accelerated Weathering (Enclosed Arc Apparatus).

Test 2: ASTM D 523-67, Standard Method of Test for Specular Gloss.

Commentary: The criterion for gloss is based upon both single- and double-carbon arc accelerated weathering devices.

By convention, precise measurements of specular gloss below 30 scale units should be done at an angle of $85^{\circ}$. Although the glosses of the 
decorative coatings for most specimens of cladding that were tested were less than 30 scale units, measurements of gloss at $60^{\circ}$ sufficed to follow the gloss changes during testing, and to detect significant variations in gloss retention.

\subsection{Color Changes}

Requirement: The decorative coating shall maintain a uniform, acceptable appearance under the effects of environmental weathering.

Criterion: The coating shall not show a change of more than 5 NBS color units after 1000 hours of accelerated weathering.

Test 1: Federal Test Method, $141 \mathrm{a}, 6152$, Accelerated Weathering (Enclosed Arc Apparatus).

Test 2: ASTM D 2244-68, Instrumental Evaluation of Color Differences of Opaque Materials.

Commentary: The criterion of 5 NBS color units represents a change in color which should be visually distinguished from the original color of the cladding.

\subsection{Impact Resistance}

Requirement: The adherence and flexability of the applied coating shall enable it to withstand rupture upon normal impact.

Criterion: The applied organic coating shall withstand a force equivalent to 70 inch pounds without exposure of the metallic substrate. 
Test: ASTM D 2794-69, Resistance of Organic Coating to the Effects of Rapid Deformation (Impact). Detection of coating rupture by use of a holiday detector appropriate to the coating thickness.

Commentary: The force chosen as criterion represents the approximate midpoint between the main groupings into which the test points of the Iaboratory test program fall. It represents a minimum force. Impact damage will also depend upon the type and thickness of the metallic substrate.

\subsection{Abrasion Resistance}

Requirement: The applied coating shall withstand environmental abrasive action that shall effect its removal.

Criterion: The organic coating applied to the metal substrate shall resist abrasion at a rate of 4 seconds per mil of coating, under the following test procedure and parameters.

Test: Federal Test Method, $141 \mathrm{a}, 6193$, Abrasion Resistance (Jet Abrader). In using this test procedure the following test parameters should be.used to meet the criterion: gas pressure of carbon dioxide propellent, 30 psi; distance and angle between jet nozzle and specimen surface, 0.8 inches and $90^{\circ}$, respectively; voltage setting on abrasive reservoir, 30 volts.

Commentary: A resistance of 4 seconds per mil of coating is the approximate midpoint of the laboratory test results on abrasion (Figure 2). 
Such a resistance should meet normal usage for siding. Where windblown sand or similarly abrasive environment may be a problem, special precautions should be taken .

\subsection{Salt Spray Resistance}

Requirement: A salt water atmosphere shall have no deleterious effect upon the exterior of the cladding system.

Criterion: The applied coating shall maintain its adherence to the metal substrate without blistering and in itself suffer no degradation after 1500 hours in a 5 percent salt spray atmosphere at $94^{\circ} \mathrm{F}$.

Test 1: ASTM B-117-64, Standard Method of Salt Spray (Fog) Testing.

Test 2: ASTM D 714-56, Evaluating Degree of B1istering in Paints.

Commentary: The salt spray test should not be confined to testing cladding intended for use in seacoast environments. It is an excellent test method for detecting breaks in the applied coating and for testing the adhesion of coating to substrate. Blistering of the applied coating from the salt water atmosphere may be evaluated by ASTM D-714-56, Evaluating Degree of $\mathrm{Bl}$ istering in Paints.

\subsection{Moisture Resistance}

Requirement: The decorative surface of a cladding system shall remain physically unaffected by normal environmental moisture. 
Criteria: Fifteen hundred cycles of condensation and drying of moisture on a coated surface at $100^{\circ} \mathrm{F}$ shall induce no color change greater than 2 NBS units and no gloss change greater than 3 gloss units, and no physical degradation of the coating.

Test 1: ASTM D 2247-68, Testing Coated Metal Specimens at 100 percent Relative Humidity

Test 2: ASTM D 2244-68, Instrumenta1 Evaluation of Color Differences of Opaque Materials.

Test 3: ASTM D 523-67, Standard Method of Test for Specular Gloss.

Commentary: The limits used as criteria in color and gloss changes are the maximum changes observed in the laboratory test program. The moisture resistance test, when run at $100^{\circ} \mathrm{F}$, effected little change in the color or gloss of the test samples. However, it is known that higher test temperatures can lead to pronounced changes in the coatings. The ease with which the test procedure may be conducted, and its potential usefulness in detecting coating problems, merit its inclusion in a testimg program for coatings.

\section{ACKNOWLEDGMENT}

The initiator of this program was Mr. Joseph W. Pitts, Metallurgist, who reported the bulk of the laboratory measurements in a preliminary report. Mr. Pitts was also responsible for shipping most specimens to the NBS Exposure Stations. 
Mr. Leopold Skoda, Materials Research Engineer, gave generously of his time and his knowledge of cladding materials. Both he and Mr. Ramon Cilimberg, Metallurgist, assisted in certain aspects of the 1 aboratory test program, as well as taking part in several field inspection tours.

The numerous individuals in the cladding industry who generously supported this program, and the military and civilian personnel who made the field inspections tours possible are also thanked. 

APPENDIX A

\section{LABORATORY TEST PROGRAM}

\section{A.1 Scope of Laboratory Testing}

Al1 1 aboratory testing was done at the National Bureau of Standards. Test samples for 1 aboratory evaluation were cut from commercial industrial cladding and were subjected to test procedures that would evaluate the integrity of the applied organic coatings. The test procedures included examining the coating of the untested cladding specimens for coating continuity, determining the resistance of the coating to impact and abrasion, and evaluating the effect of accelerated weathering and water permeation on the color and gloss of the specimen coating. The resistance of the cladding systems to a salt water atmosphere was also studied. Laboratory test procedures were run in accordance with ASTM or Federal Test Method procedures unless otherwise noted.*

\section{A.2 Applied Coating Continuity}

Any minute breaks or pinholes in a coating that penetrate to the substrate are called holidays. Commercial instruments are available for detecting such holidays. A battery-powered portable holiday detector was used in this 1 aboratory program for examining the cladding systems for breaks in the applied coatings.

There was no ASTM or equivalent official test procedure to follow in testing for holidays. The procedure that was used consisted in attaching

*There was a variation in specimen adaptability to each test procedure, hence, the dissimilarity in the number of samples reported for each test. 
one electrode of the holiday detector to the metal substrate of a specimen and the second electrode to a wet sponge. When the sponge was pressed over the organic coating, water that penetrated through any break in the coating to the substrate closed the detector circuit, activating an audio signal. The procedure was both simple and rapid, although it yielded only qualitative results. The low voltage of the electrical circuit affected neither coating nor substrate.

Many of the cladding specimens received from commercial suppliers were embossed or formed into some architectural profile. Holiday testing showed that the coating in these formed areas or along panel bends was prone to holidays. Of 25 separate cladding systems that were tested for holidays before exposure, specimens of 8 systems had breaks in the coatings, principally along the longitudinal bends of the cladding panel.

Although potentially useful as a requirement for cladding systems, testing for coating continuity is, as yet, not quantitative. For this reason it was not included in the performance specification. The qualitative aspect of the holiday detector did justify its use in other facets of the testing program where penetration of the coating was in question.

\section{A.3 Resistance to Impact}

The force necessary to rupture the applied coating of the cladding specimens was measured in inch pounds. The procedure and equipment described in ASTM Method D 2794-69, Resistance of Organic Coatings to the Effects of 
Rapid Deformation (Impact), was used, with the modification that penetration of the coating at the point of intrusion was determined with a portable holiday detector.

The results of the 1 aboratory testing for impact resistance is given in figure $1 *$, in bar graph format.

\section{A.4 Abrasion Resistance}

The resistance of the coatings to abrasive forces was determined for each cladding system by using the procedure outlined in Federal Test Method, 141a, 6193, Abrasion Resistance (Jet Abrader).

By using this procedure it is possible to measure the abrasion resistance of a coating with only a small test specimen. This capability was an advantage with those cladding systems in which embossing or panel profiles made it difficult to use effectively the falling sand or Taber abrasion determining procedures. The jet abrader procedure measured the time necessary for a jet of gas propelled abrasive particles to pierce the coating to the metal substrate.

In this laboratory procedure the four instrumental parameters that can be varied (and the settings used in these tests) were: pressure of carbon dioxide gas propellent (30 psi), distance and angle between jet nozzle and specimen ( 0.9 inches and $90^{\circ}$, respectively), and the voltage setting on the abrasive reservoir (30 volts).

*A11 figures can be found in Appendix F. 
From the measured time for penetration of the coating and the known thickness of the coating, the time necessary to abrade one mil of coating was calculated. The abrasion resistance of the cladding specimens tested in the 1 aboratory is given in decreasing values of seconds per mil of coating in figure 2 .

\section{A.5 Salt Spray Resistance}

In determining the resistance of cladding to a salt water atmosphere, the procedure of ASTM B-117, Standard Method of Salt Spray (Fog) Testing, was followed.

For each cladding system two specimens of cladding, $3 \times 8$ inches, were exposed for 1500 hours to a 5 percent sodium chloride atmosphere at $94^{\circ} \mathrm{F}$. One specimen was unmarked with the cut edges wax coated; the field of the second specimen was scribed in a figure $X$ and the cut edges were left unprotected. Upon completion of a test run the condition of the respective test panels was assessed both in the areas of the scribe mark and cut edges and in the unmarked field. A subjective rating was given each area on a scale from 1 (excellent) to 10 (poor). In two series of tests, using the.same criteria for evaluation, essentially equivalent results were obtained.

The results of the salt spray tests are given in decreasing the order of acceptable behavior in figure 3. The evaluation of field and scribed areas is listed separately for each specimen. 
The severity of the salt spray test for claddings is illustrated in figures 4 and 5. In the section of untested cladding specimen pictured in figure 4, cracks in the coating extended along the longitudinal panel bend. Use of a holiday detector indicated that these cracks penetrated to the substrate. After 150 hours in a $5 \%$ salt spray atmosphere at $94^{\circ} \mathrm{F}$, the coating along these cracks had blistered and some had flaked off (figure 5).

\section{A. 6 Accelerated Weathering}

Single- and double-carbon arc accelerated weathering devices were used to subject the cladding specimens to the combined effects of 1000 hours of ultraviolet radiation and moisture. The test procedure followed ASTM D-822, Recommended Practice for Operating Light- and Water-exposure Apparatus (Carbon Arc Type).

The single enclosed carbon arc was operated for 20 hours a day, during a five-day week, with alternate cycles of one hour light, one hour darkness. A relative humidity of $95-100 \%$ was maintained in the test chamber by continually spraying water on the back of the rotating specimen holder. Water was not sprayed directly on the test specimens.

The double enclosed carbon arc was operated in accordance with Federal Test Method, 141 a, Method 6152, Accelerated Weathering (Enclosed Arc Apparatus). Test specimens were exposed for a 20 hour day, five-day week, with continuous 1 ight and 9 minutes of direct water spray on the specimens every hour. 
Color and gloss differences were measured after both accelerated weathering procedures. The difference in color, in NBS units, between a tested specimen and the control coupon for that cladding system was measured at a reflectance angle of $45^{\circ}$, in accordance with the test procedure described in ASTM D 224-68, Instrumental Evaluation of Color Differences of Opaque Materials. A high sensitivity color difference meter was used in making the color measurements. The $60^{\circ}$ specular gloss of both test sample and control coupon were measured, using a precision gloss meter, in accordance with the procedure outlined in ASTM D523-67, Standard Method of Test for Specular Gloss. NBS secondary working standards were used to standardize the test instruments for both color and gloss measurements.

Before making color and gloss measurements, the test specimens were cleaned with a soft paper towel and $1 \%$ detergent solution, rinsed with distilled water, and air dried. Buffing the coated surfaces of the test specimens was avoided.

The changes in coating gloss and color after exposure to accelerated weathering are given in a bar graph format in figures 6 and 7 . In both figures the test results are arranged in decreasing order of the gloss values of the coatings before testing.

\section{A. 7 Moisture Resistance}

$\mathrm{Cl}$ adding systems were tested for their resistance to the effects of moisture by using the procedure of ASTM 2247-68, Testing Coated Metal 
Specimens at 100 percent relative humidity. Single 2 x 8 inch samples of cladding were exposed for 1500 one hour cycles of condensation and drying in humidity cabinet at $100^{\circ} \mathrm{F}$. Only the decorative coating side of the specimens was exposed to the humidity cabinet atmosphere.

Gloss and color difference measurements were made of the specimen coatings after testing. The gloss values, both before and after testing, are given, together with the color differences values, in figure 8. 



\section{APPENDIX B}

NATURAL WEATHERING EXPOSURE PROGRAM

\section{B.1 NBS Exposure Stations}

Specimens of cladding, identical to the industrial cladding subjected to accelerated weathering in the laboratory program, were exposed to natural weathering at the seven exposure stations maintained by the National Bureau of Standards throughout the United States and in Puerto Rico. These exposure stations provided the diversity in environmental and climatic conditions wanted for meaningful results in material weathering tests. The stations' locations and climatic classifications (following Trewartha*) are:

Fort Lewis, Washington -- marine west coast (cool summer). Roosevelt Roads, Puerto Rico =- tropical, monsoon seashore climate Nellis Air Force Base, Nevada -- subtropical desert

Fort Greely, Alaska -- subartic - no dry season

Fort Holabird, Maryl and -- humid subtropical (warm summer)

Gaithersburg, Maryland -- humid subtropical (warm summer)

U. S. Coast Guard Receiving Center, Cape May, New Jersey -subtropical (warm summer)

*G. Greathouse and C. Wessel, "Deterioration of Materials, Causes and Preventive Techniques," plate one, Reinhold, N. Y., 1954. 
Although the last three named stations have the same climatic classification, environmentally they are different. Fort Holabird is in an industrial location, Gaithersburg in a rural area, and Cape May on the seashore.

Al1 exposure stations are in essentially rural locations on U. S. Government reservations, with the aforementioned exception of the Fort Holabird exposure station, pictured in figure 9. At Fort Holabird, in an industrial zone of Baltimore city, windborne particulate matter and air pollution are major factors in the weathering process.

The Puerto Rico and New Jersey exposure stations are both adjacent to the ocean. The elevation of the Puerto Rico station, 120 feet above sea level, precludes direct ocean spray on the samples. At the New Jersey station there are two series of sealevel exposure racks, at 80 and 800 feet from the shoreline.

\section{B.2 Specimen Mounting and Evaluation in Natural Weathering Exposure}

One foot by two foot panels of cladding were sent to the exposure stations as each system was received for testing at NBS. The specimens were exposed in a vertical position with the coated side facing south. As all cladding systems were not received simultaneously, it was not possible for aI1 cladding systems to receive the same period of exposure at all exposure stations, hence the variation in the number of specimens exposed at each station.

Although the time period for natural weathering was restricted to one to two years, the time was sufficient to indicate defects in the applied 
coating. Following weathering and return of the specimens to NBS, gloss and color changes were measured, and the coatings tested for breaks with a portable holiday detector.

The gloss and color difference measurements are presented in the same bar graph format as the corresponding measurements of the accelerated weathering studies; the results for each station are given in figures 10 through 17 .

\section{B.3 Specific Instances of Degradation from Natural Weathering}

The tendency of coatings to degrade at the bends or in the formed sections of industrial cladding panels was discussed in relation to the 1 aboratory tests on coating continuity (A.1) and resistance to salt spray (A.5). Samples exposed to natural weathering underwent similar degradation, as shown by testing for coating continuity. Of 160 test panels, 98 panels (61\%) had some break in the coating following weathering; 38 panels (24\%) had breaks only at the panel bends. These breaks were extensive, not isolated to one segment of the panel surface.

The coatings on unweathered specimens of the claddings pictured, after weathering, in figures 18 and 19, was found to be continuous. Specimens of this cladding when subjected to the same holiday test procedure did have breaks in the coating along the longitudinal bends of the panel after weathering. The specimen of this cladding shown in figure 18 was exposed for 19 months at the 80 foot New Jersey exposure site. Corrosion has begun along the panel bends where the coating has degraded; there was al so some spalling of the coating along the cut edges. The longitudinal 
cracks in the coating (pictured horizontally), blisters, and corrosion along the bends are all visible in figure 19.

An example of almost complete coating degradation is illustrated in figure 20. The specimen's exposure conditions were also 19 months at the New Jersey 80 foot site. There has been considerable color fade, chalking, and pitting of the coating, with substrate corrosion both at the pane1 bends and at the cut edges.

Figure 21 illustrates a case of coating degradation in which the applied coating was evidently unstable to weathering. A11 specimens of this cladding system that had been exposed to natural weathering were found to be in poor condition. Before 1 aboratory testing or natural weathering this siding system had cracks in the coating which holiday testing indicated penetrated to the metal substrate. Weathering caused considerable chalking, color change, blistering and pitting of the coating. This effect of weathering is best illustrated by a panel exposed for 19 months at the seaside New Jersey site. The arrows in figure 21 indicate the approximate line of demarcation between the darker area of the coating (to the 1 eft) that was open to weathering, and the 1 ighter area (to the right) that was protected by the flap holding the panel on the exposure rack. Enlargement of a segment of this demarcation line is pictured in figure 22. B1isters formed under the flat were unbroken (downward arrows); blisters in the exposed area have broken, exposing the bare metal of the substrate (upward arrows); horizontal arrows indicate cracks in the coating. 
The only instance of impact damage to cladding that occurred during natural weathering exposure is pictured in figure 23. The surface depressions in this panel of 1 ight gauge cladding ( 0.018 inch metal substrate) are thought to have been due to golf balls from a golf driving range near the exposure racks. (The racks have since been moved to another location.) Heavier gauge cladding, mounted adjacent to panel in figure 23, did not show this damage.

One instance of coating degradation that occurred during natural weathering was caused, evidently, not by the environment or climate alone. When the panel pictured in figure 24 was mounted at the Gaithersburg exposure station, a factory-applied transparent plastic film, intended to protect the coating finish during transit and erection, was not peeled off. This protective film was removed from a panel of the same cladding mounted nearby. After two years of weathering, this 1 atter panel showed no coating degradation. The panel on which the film had been left had serious degradation of the coating (figure 24). Where the panel was covered by the flap of the exposure rack some of the protective film was still present and the coating of the panel has not degraded (from 18 to $25 \mathrm{~cm}$. on the scale in figure 24). Where the panel had been fully exposed to weathering (10 to $18 \mathrm{~cm}$.), the protective film had weathered away and the applied organic coating had been seriously degraded. The exact nature of this degradation is not known, although it is evident that non-removal of the protective film was a factor in its cause. 



\section{FIELD INSPECTION TOURS OF IN-SERVICE CLADDING}

\section{C.1 Inspection Areas and Procedure}

As a practical evaluation of cladding systems, structures incorporating cladding similar to the claddings investigated in the laboratory and natural weathering phases of this program were inspected. Although exact duplication of claddings could not always be obtained, the problems and failures that were observed were useful in establishing a basis for comparing the durability of the various cladding systems.

Field inspection trips were made to the metropolitan areas of Baltimore, Washington, Philadelphia, and Norfolk. Sites along the Gulf Coast of Florida and in Puerto Rico were also visited. When the field trips were arranged by the firms that had supplied the cladding used in the structures, background information relating to the manufacture and coating of the cladding was easily obtainable. Personnel on military bases proved helpful but could not always provide this type of information. Inspections were limited to the obvious defects and deficiencies of the siding systems, and were often subject to military or commercial restrictions. When permitted, photographs were taken of particular deficiencies characteristic of claddings in general, including color and gloss changes, and spalling and impact loss of the coatings. Also noted were the effects of climate or environment on the cladding. 
Although the structures inspected were predominately used for 1 ight industry, such as machine shops, repair shop facilities and warehouses, non-industrial structures were also inspected. These included military offices, recreational facilities, and scientific research complexes, and even a casket manufacturer. Environments of the buildings inspected varied from heavy industrial to rural.

\section{C.2 Cladding Failures Observed}

The effect that climate can have upon uncoated metal cladding is illustrated in figure 25. This building, in Puerto Rico, was constructed of uncoated metal cladding; three months following erection, every siding panel was corroded. A nearby structure, constructed with factory-coated cladding, has, after three years weathering, wall panel corrosion only where the applied coating has been 1ost. In figure 26, one segment of the building wall, where corrosion has occurred in an area without coating, is pictured together with an adjacent coated panel.

Some industrial environments afford corrosion problems that no cladding system can 1 ong protect against. For example, the cladding used to cover a steel mill hot-coke conveyor belt must be replaced biannually. The corrosive fumes from these coke ovens also attacked the cladding used in nearby storage buildings (figure 27). Another example of a severe though more localized industrial environment is shown in figure 28. Cladding over a heat exchanger exhaust was corroded, discolored, and mildewed. Nearby cladding remained in excellent condition. 
Salt water environments can present special problems both for the metal substrate and for the applied organic coating. The cladding pictured in figure 29 was used in a building located several hundred feet from an ocean inlet. After five years in service, the coating shows heavy chalking and slight color fade. Corrosion of the substrate has occurred where the coating was abraded. The airplane hangar pictured in figure 30 is in the same general area, within a mile of the ocean. In enlarging the facility an attempt was made to duplicate the color of the original cladding. Due to fading of the original coating, there was a significant difference in color between the new and old cladding (figure 31).

The effect that color fade of the decorative coating can have on the overall appearance of a building is illustrated in figure 32, where the walls are marked by prominent horizontal bands of fading.

The results of natural physical impact upon coated cladding can be seen in figures 33 and 34. A brief but violent hailstorm impacted hailstones against only one side of the panel contours with force sufficient to dislodge the coating.

Spalling may occur when the coating manufacturer's recommendations for application of the coating to the substrate have not been followed. This is illustrated in figure 35. The wall panels and spacers have the identical coating, but according to the coating manufacturer's representative, the spacers were coated without the recommended priming of the substrate. 



\section{APPENDIX D}

CORREJATION OF ACCELERATED AND NATURAL WEATHERING TEST RESULTS

\section{D.1 Limitation of Correlation Between the Two Test Methods}

Correlation of accelerated weathering with natural weathering tests was limited by the relatively short duration of the 1 atter tests, which seldom exceeded two years. Also, the ratio of the weathering effect of accelerated weathering to natural weathering was not known. Quantitative comparison of the two was, therefore, not possible.

The sole evaluative techniques common to both weathering tests were the color and gloss measurements subsequent to the weathering tests, which allowed a qualitative comparison of the two forms of weathering.

\section{D.2 Qualitative Correlation}

In comparing the effects of accelerated and natural weathering tests on the specimen coatings, it was found that changes in gloss were more obvious than changes in color when using 1 - and 2-carbon arcs, whereas in the natural weathering the reverse was true. of all the cladding systems tested, only the two systems described below had changes in color and gloss from natural weathering that were comparable to the color and gloss changes from accelerated weathering.

Cladding System 82: Specimens were exposed at seven NBS exposure stations. At six stations, specimen color and gloss changes exceeded the limits chosen for the performance specification, i.e. 5 NBS color units and $50 \%$ gloss change. For specimens subjected to accelerated weathering, gloss 
changes exceeded $90 \%$ of the original gloss value, but no color changes were greater than 5 NBS color units.

Cladding System 55: Specimens of this cladding were exposed at six NBS exposure stations. At five stations, specimen color and/or gloss changes exceeded the performance specification criteria. For specimens subjected to accelerated weathering, gloss changes varied between $50 \%$ and $80 \%$ of the original gloss value, but no color changes were greater than 3 NBS color units. 
RECOMMENDATIONS FOR PREVENTION OF IN-SERVICE DAMAGE TO CLADDING

\section{E.1 Background}

Field inspection tours were primarily designed to evaluate the effects of natural weathering upon the durability of cladding systems, as was discussed in Appendix C. These inspections also disclosed in-service damage to cladding that was due to the usage of the structures in which the claddings had been incorporated. Such damage merits discussion, for it is an aspect of industrial cladding that the user should be cognizant of; with care and foresight such damage may be reduced, it not altogether prevented.

\section{E.2 Instances of Observed Damage and Recommendations for Its Prevention}

The observed in-service damage to cladding was caused mainly either by accidental injury from vehicular traffic, or by carelessly exposing the cladding to excessive physical conditions. Examples of both situations and suggestions as to their prevention are given below:

Where buildings were surrounded by grass plots and the wall cladding extended to ground level, there was a strong possibility for injury to the cladding from grass mowing. Such injuries were not only abrasions of the coatings (figure 36), but also deformations of the wall panels (figure 37). A gravel border contiguous to the building should eliminate injury from grass cutting by simply obviating its need. More serious was vehicle impact damage, which distorted or even dislodged cladding 
panels from the structural supports. Cladding adjacent to loading dock areas was especially prone to this type of damage, as illustrated in figure 38. Any wall surface susceptible to impact damage should be protected either by a bumper system or incorporation of more robust building materials with the cladding. Such a combination of masonry and cladding in a loading dock area is shown in figure 39. Cladding damage may also be caused by vehicle use within a structure. The prongs of the forklift truck, indicated in figure 40, have pushed out the wall cladding. An interior bumper system, or floor chocks appropriately spaced from the wall, should have prevented such an accident.

Intended as a non-load bearing structural element, a cladding system cannot withstand weight or force exceeding its intended architectural usage. In the following two examples of cladding misuse, proper supervision of plant operation was probably the only preventive technique applicable.

In the first example, several hundred feet of a manufacturing plant's exterior wall was used as a storage area. The massive units shown in figure 41 are supported only by the industrial cladding panels of the plant wall. Smaller units have been pushed against the wall at ground level, causing the cladding damage pictured in figure 42. The second example, a similar, albeit minor instance of negligence, is shown in figure 43. In 1 ieu of a proper base for anchoring a door chain, a C-clamp has been attached to the cladding, distorting the panel profile. 


\section{APPENDIX F}

FIGURES

In the caption for each figure, in parenthesis, is given the section number to which the figure refers. 
FIGURE 2 (A.4)

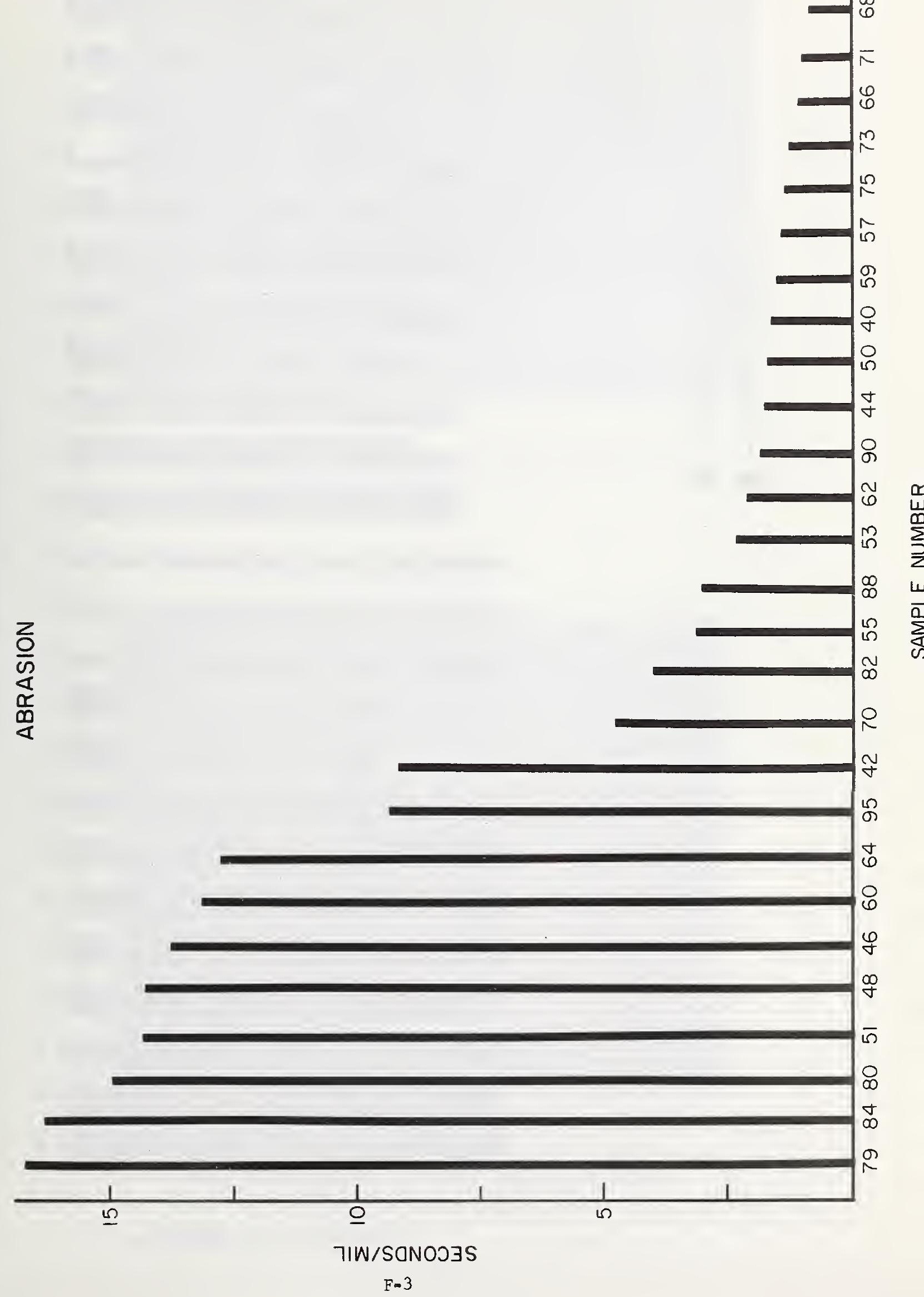


FIGURE 3 (A.5)
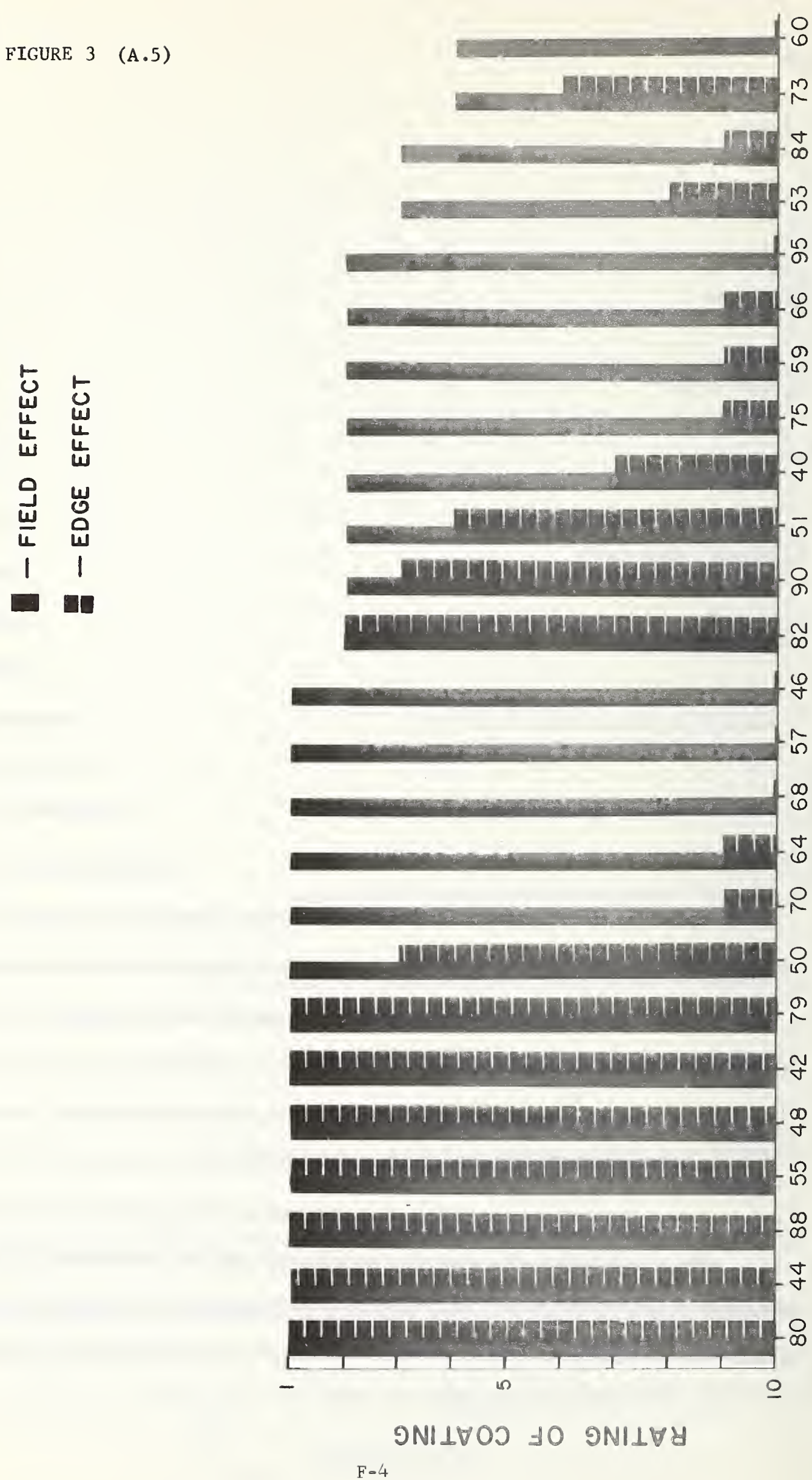


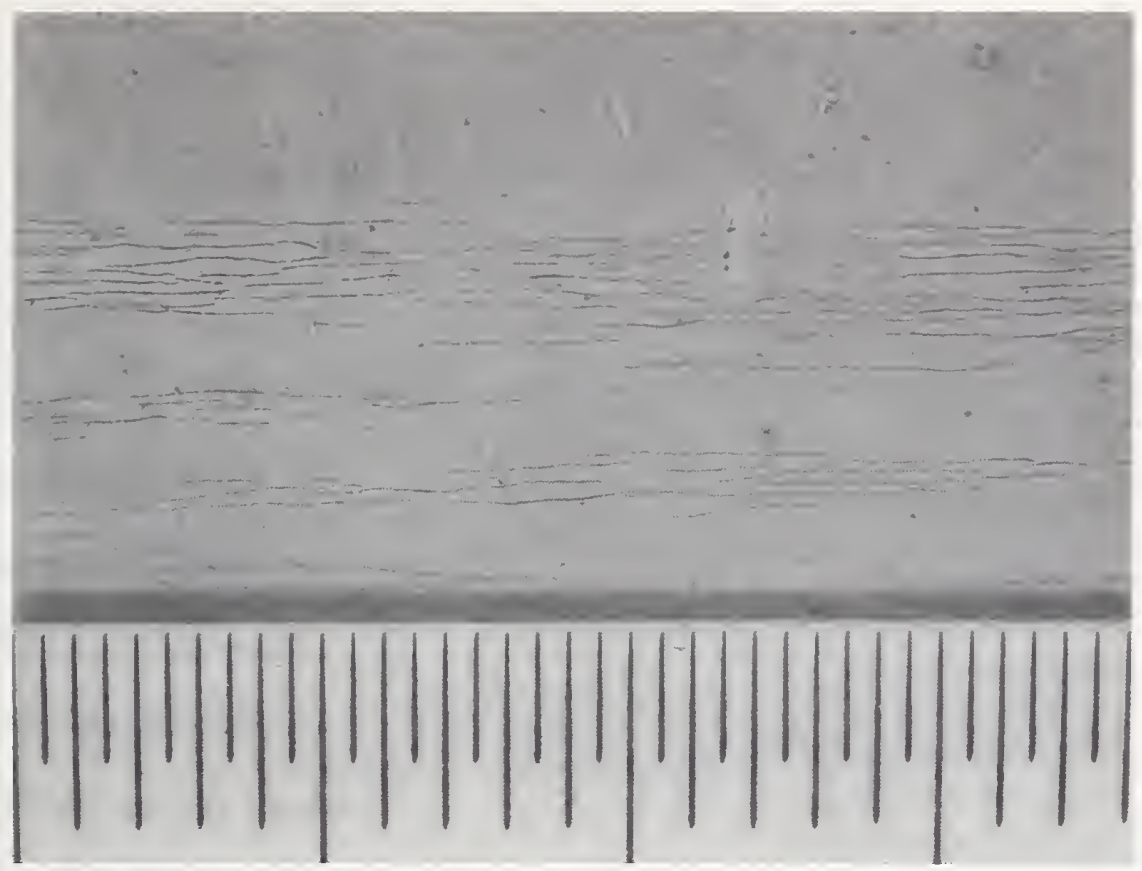

Fig. 4 - Cracks along bends of untested cladding panel. Scale divisions, $0.5 \mathrm{~mm}$. (A.5)

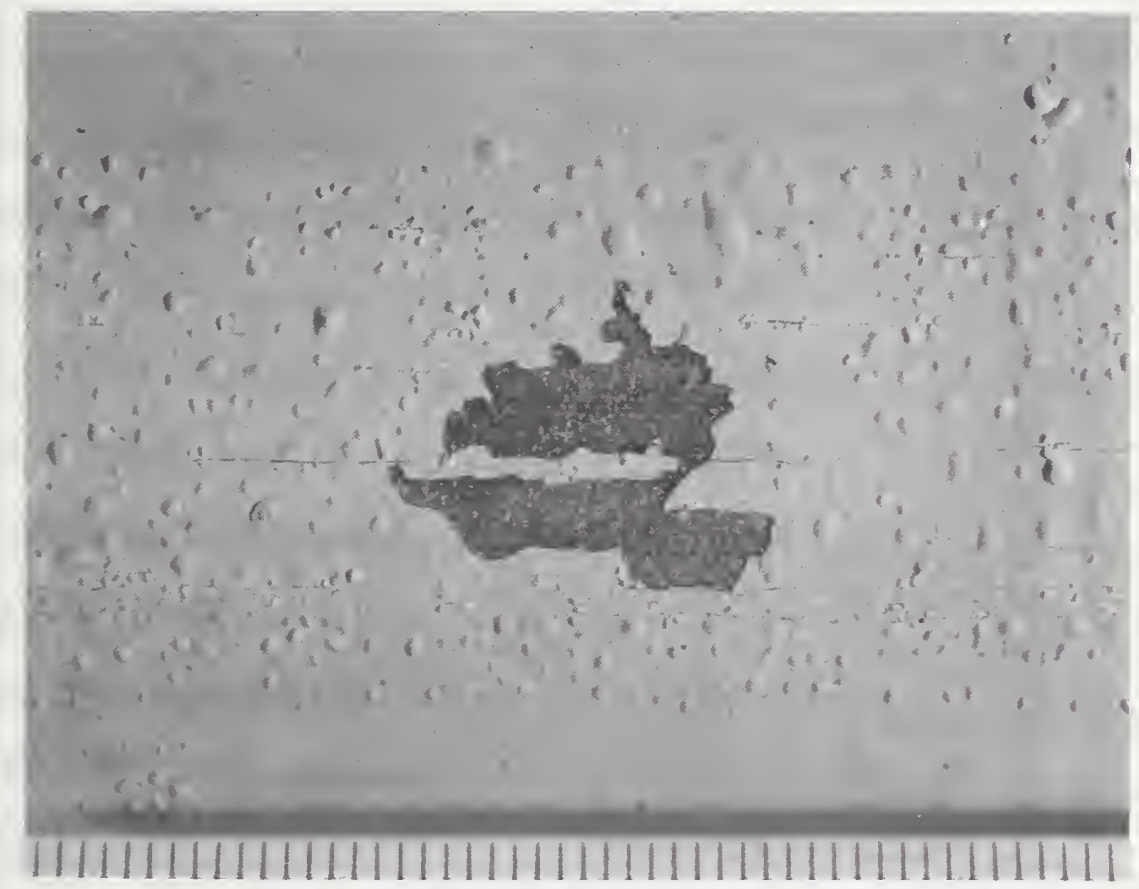

Fig. 5 - Section of cladding panel pictured in figure 4 after 150 hours in $5 \%$ salt spray at $94^{\circ} \mathrm{F}$.

Scale divisions, $0.5 \mathrm{~mm}$. (A.5) 
FIGURE $6 \quad$ (A.6)

으
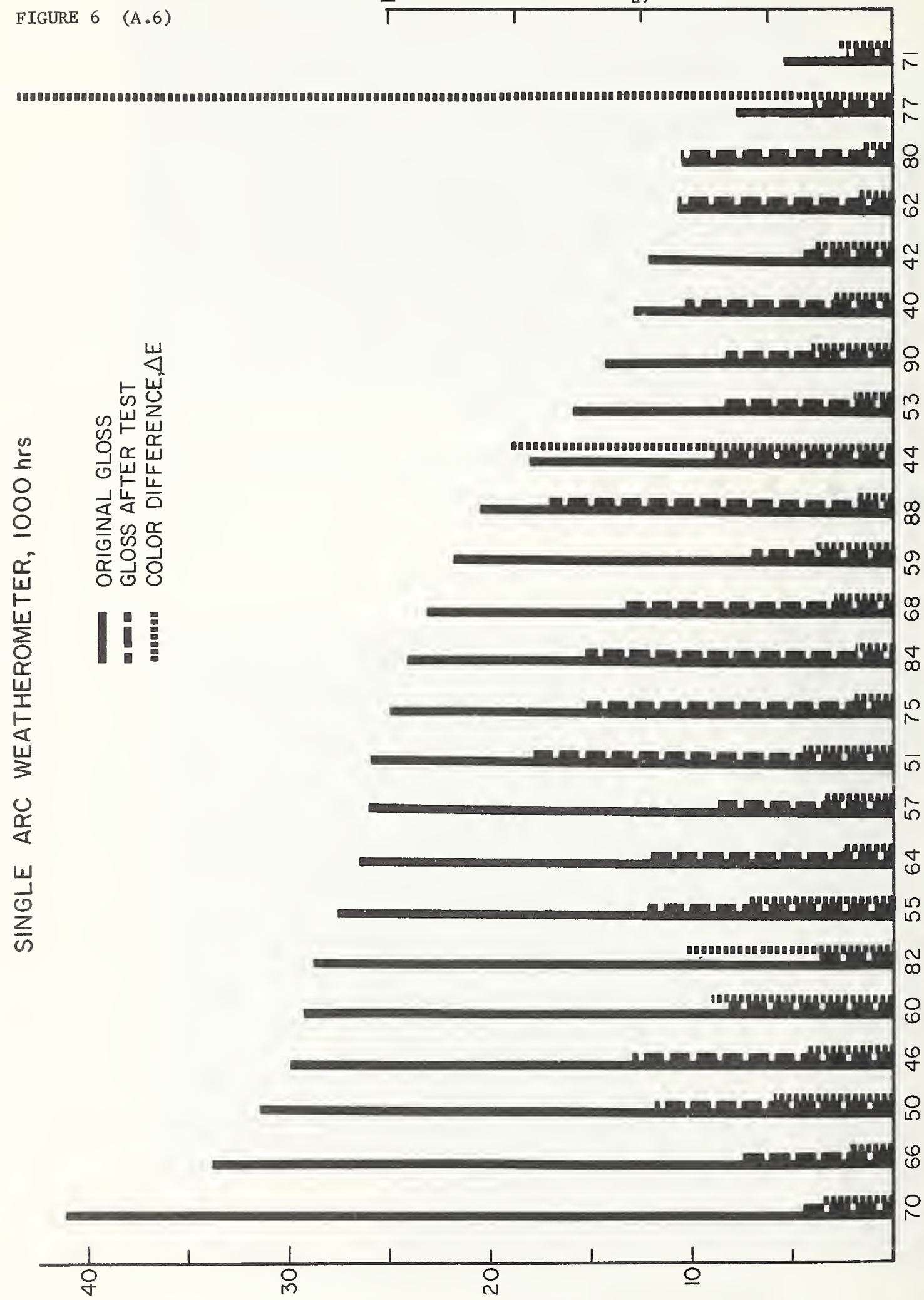
FIGURE 7 (A.6)

으 $\Omega$

i

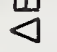

ヒே

の㞾之

ஸा

뚠

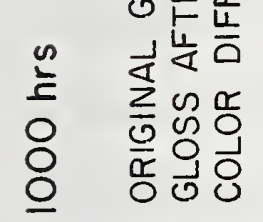

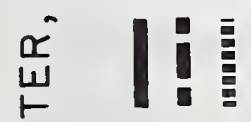

$\sum$

口

W

I

닌

3

产

$\frac{1}{3}$ 
FIGURE 8 (A.7)

은

4

占㟧

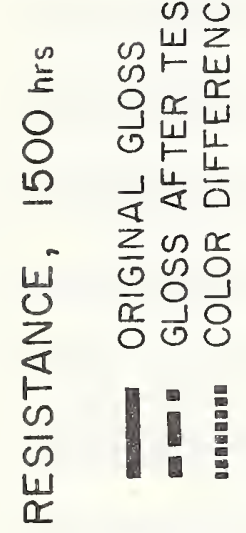

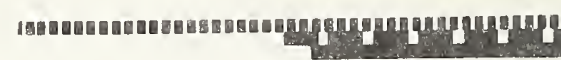
axprum $\bar{T}$

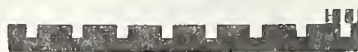

$\frac{u}{\frac{u}{\alpha}}$

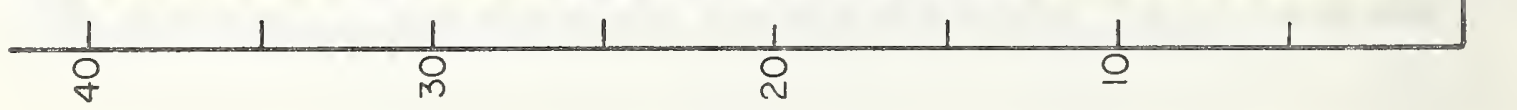




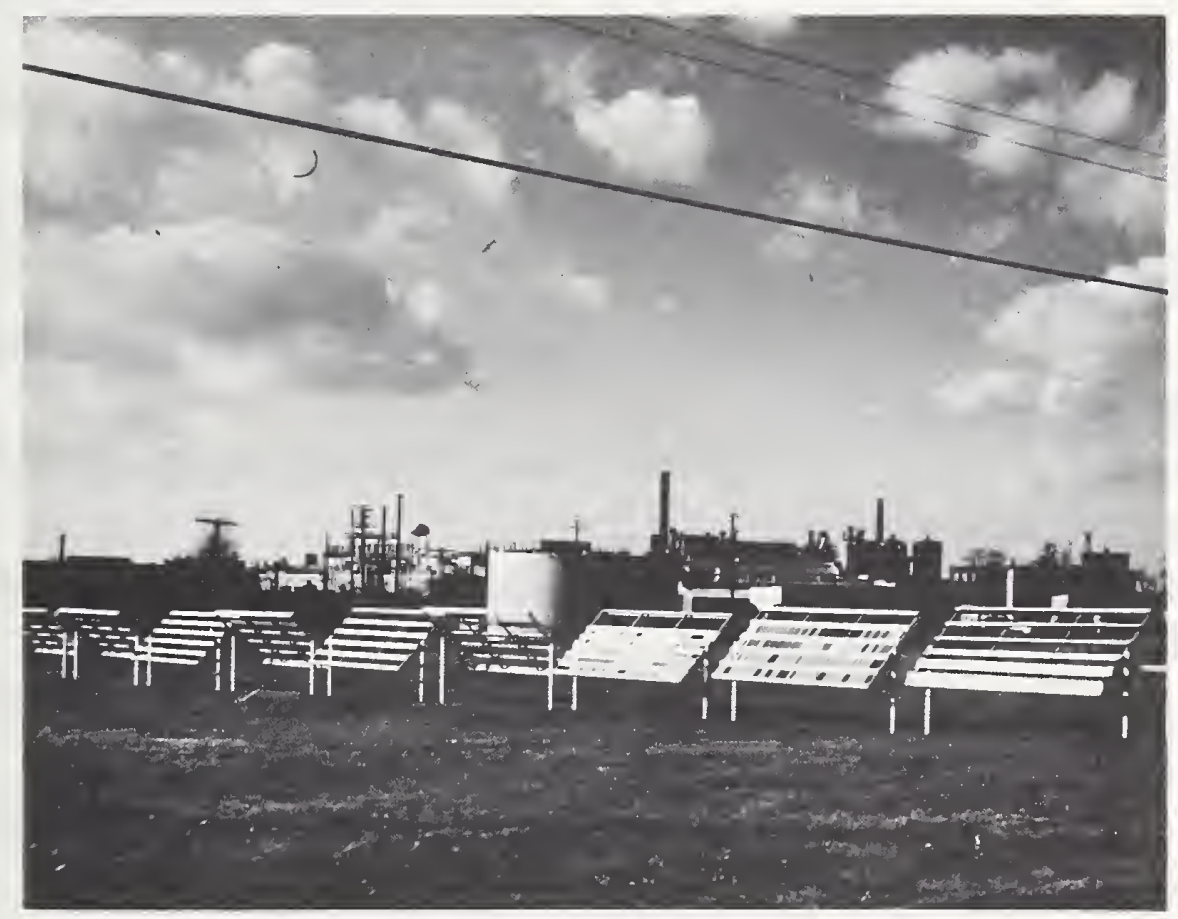

Fig. 9 - NBS Exposure Station at Fort Holabird, Baltimore Maryland in 1970. (B.1) 
FIGURE $10 \quad($ B.2)
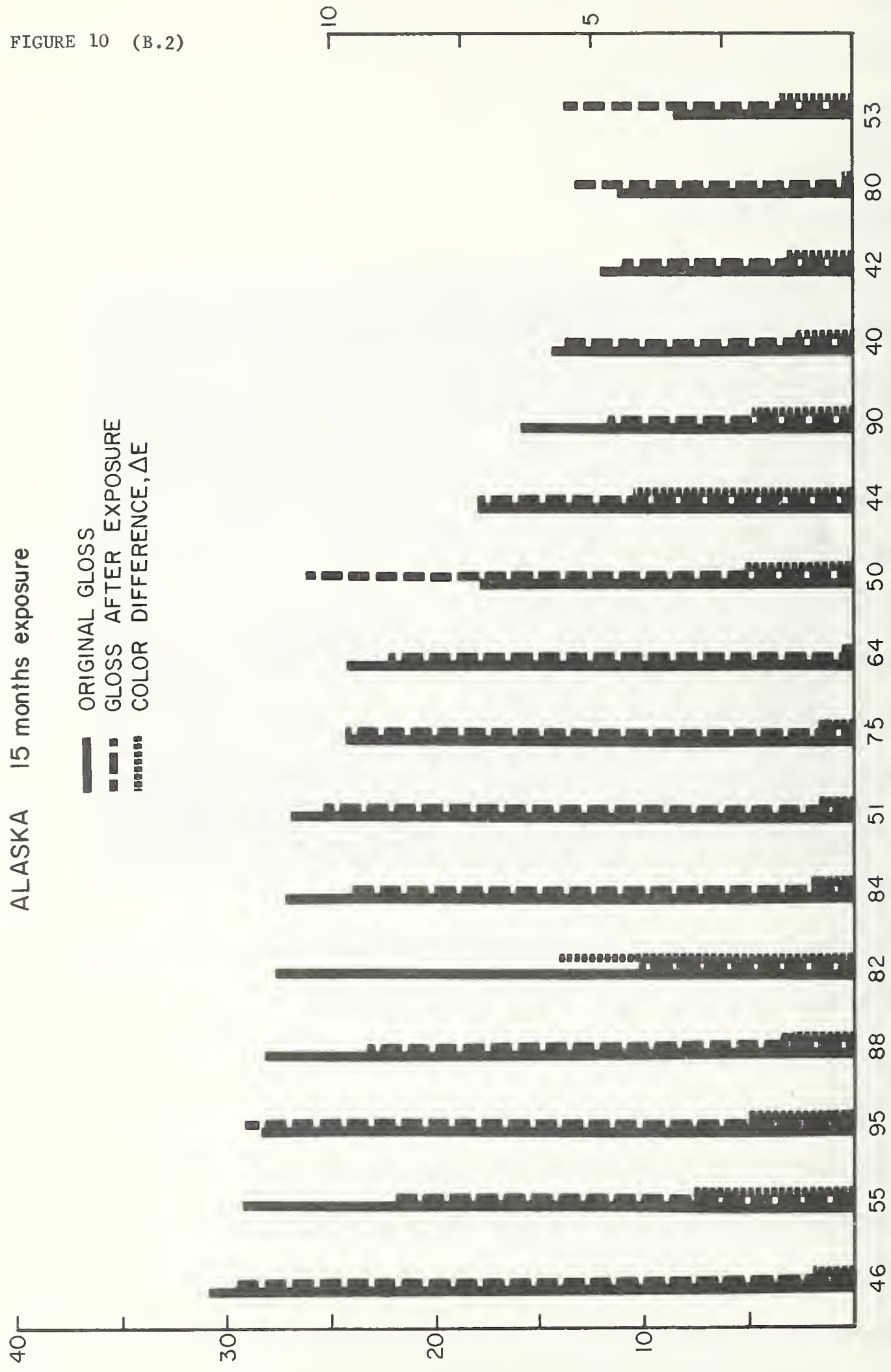
FIGURE 11 (B.2)

으

n
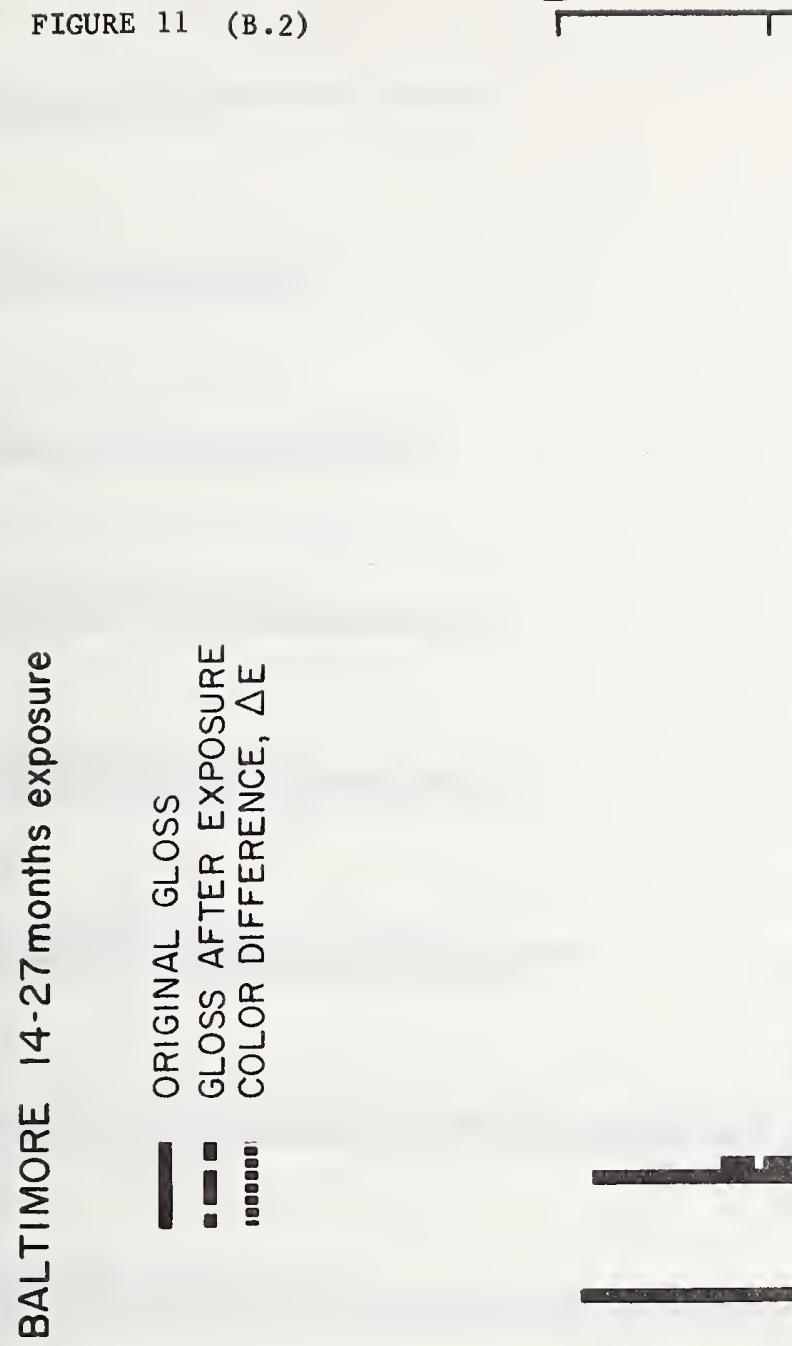

1

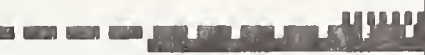

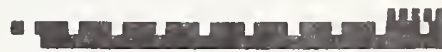

R
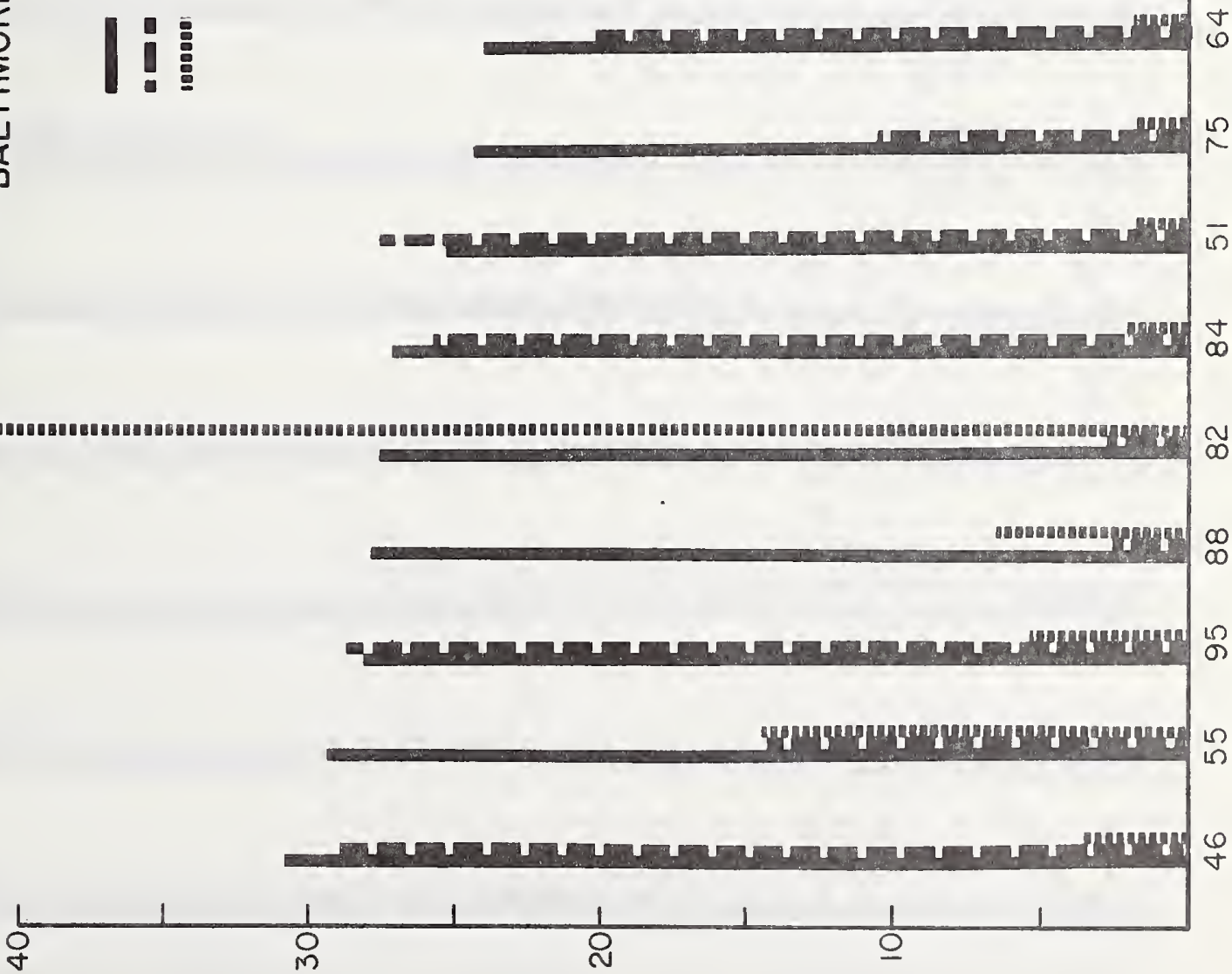

S5079 009 
FIGURE 12 (B.2)

으

\section{हI}

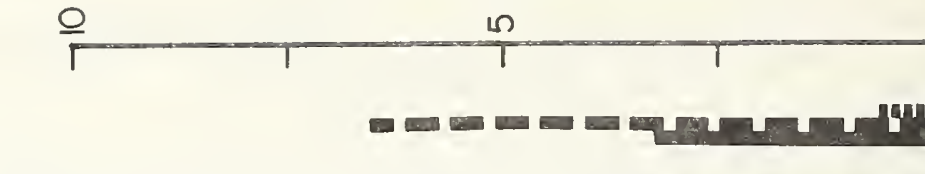

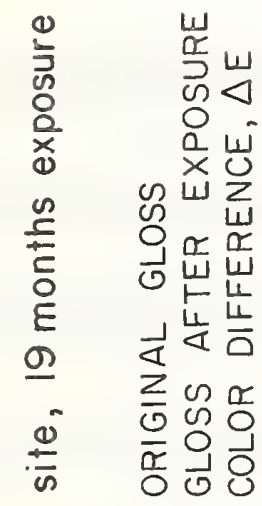

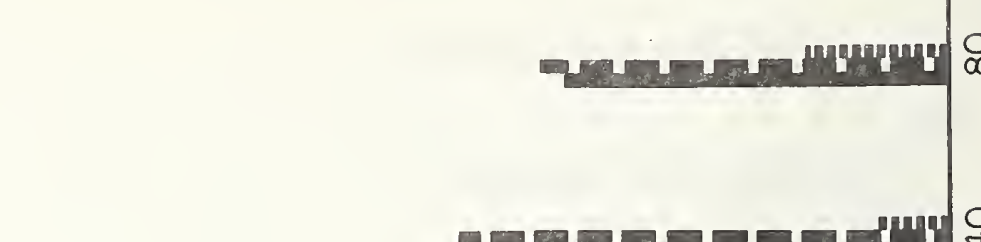

$\stackrel{\wp}{\infty}$

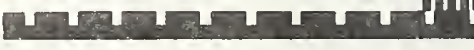

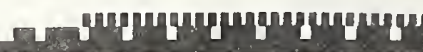

는

$\frac{2}{2}$

山

$\frac{1}{0}$
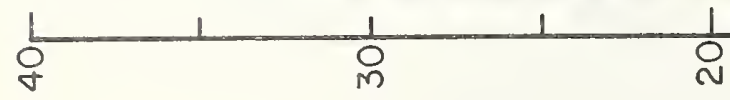

$$
\text { S5079.09 }
$$


FIGURE $13 \quad$ (B.2)

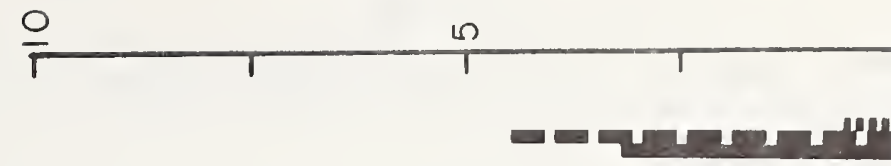

产 崩山

ฉ

×

n ल난

임

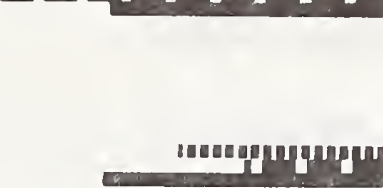

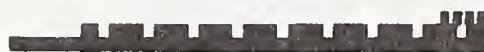

O $\sum \sin$

드용

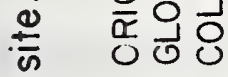

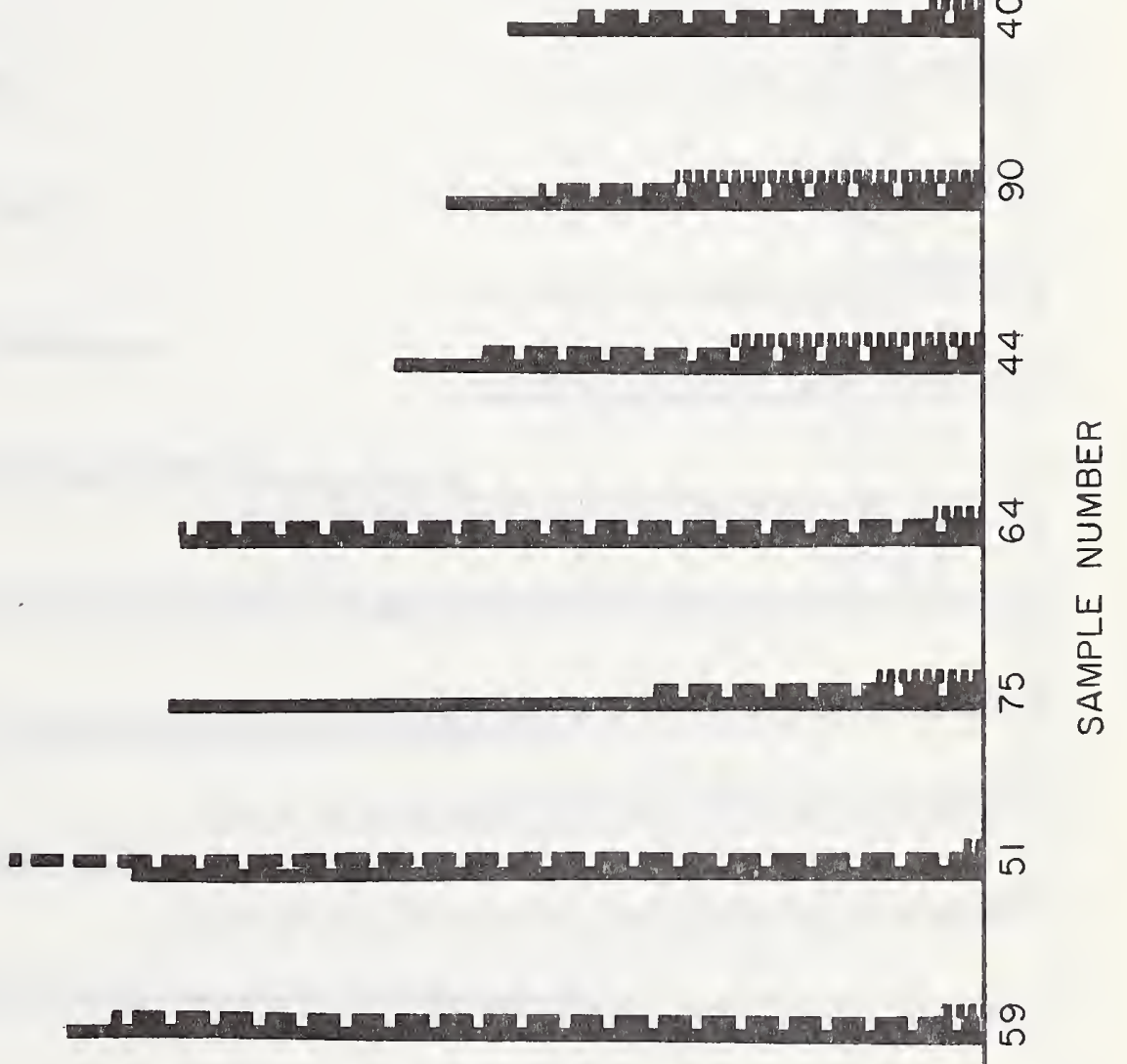

চ

○

$\sum$

U

$\frac{1}{1}$

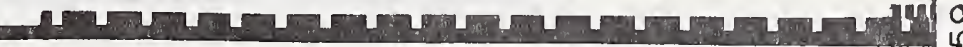

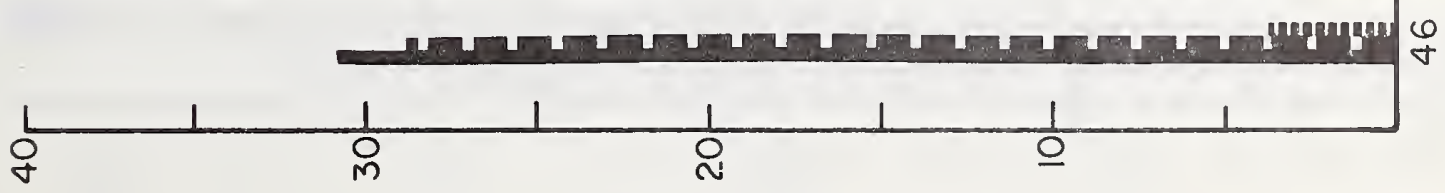




\section{FIGURE $14,(B .2)$}

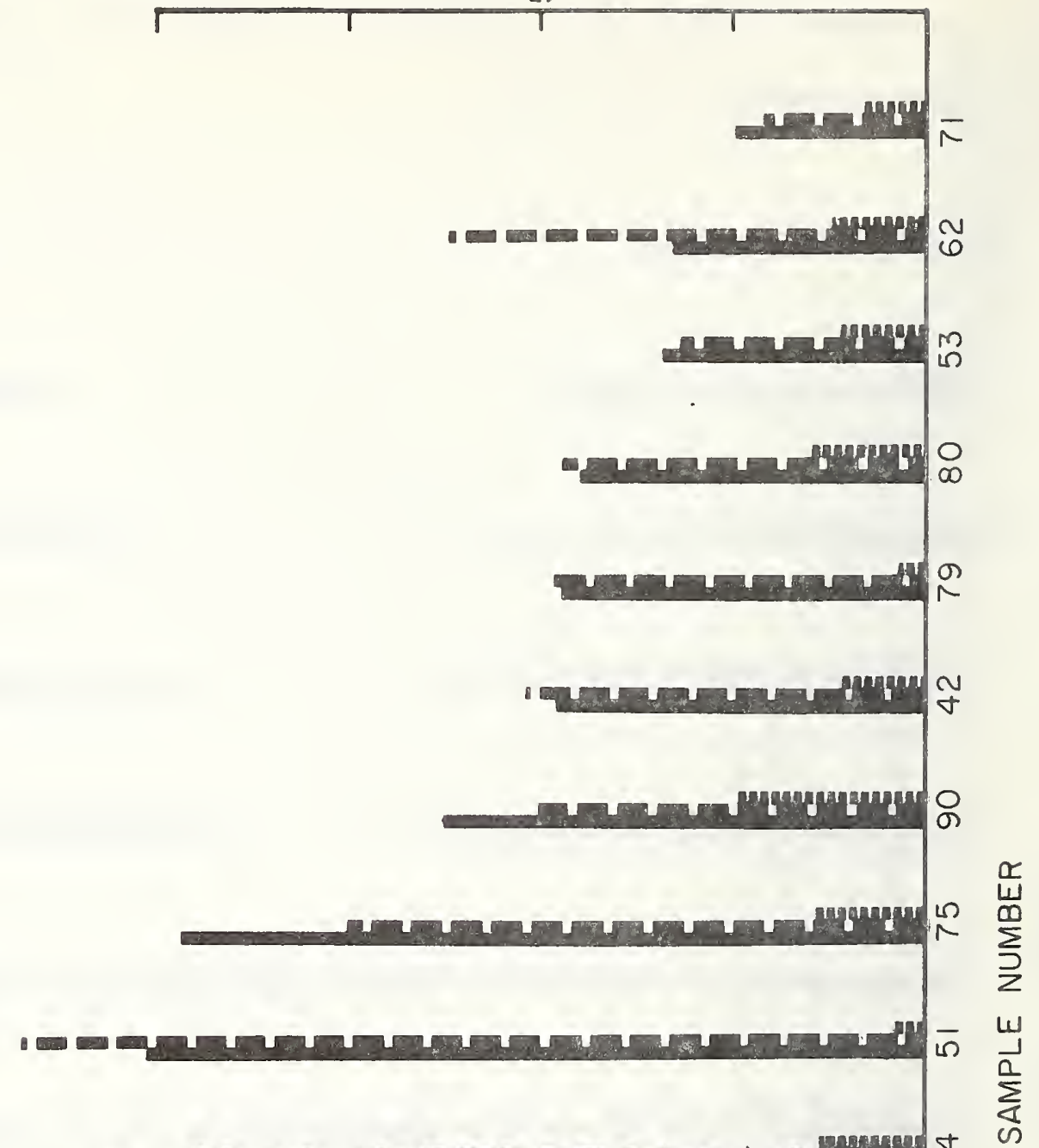

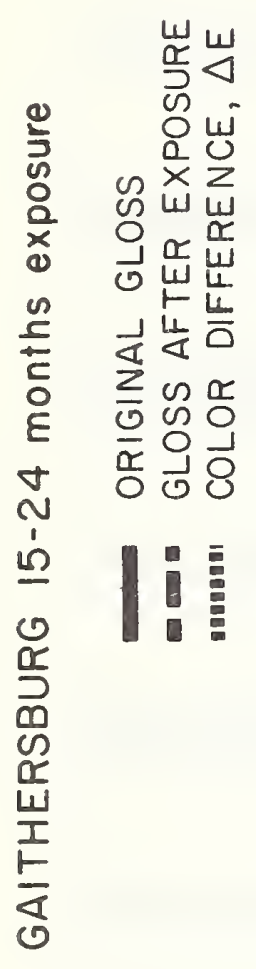

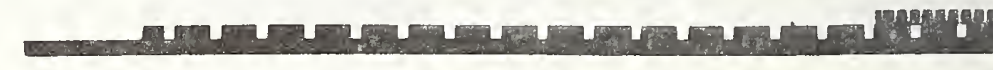

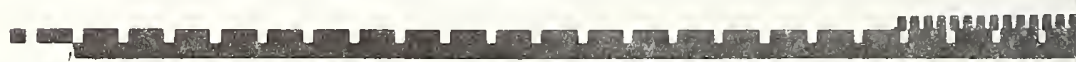

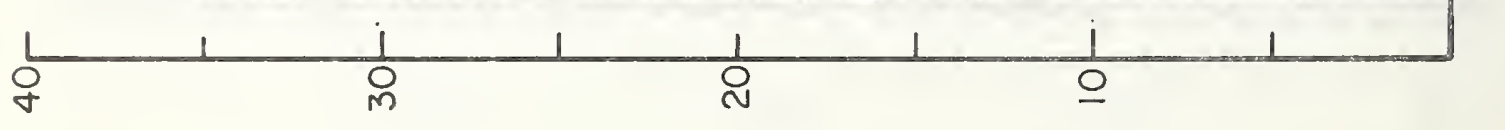


FIGURE 15 (B.2)

인

เ)

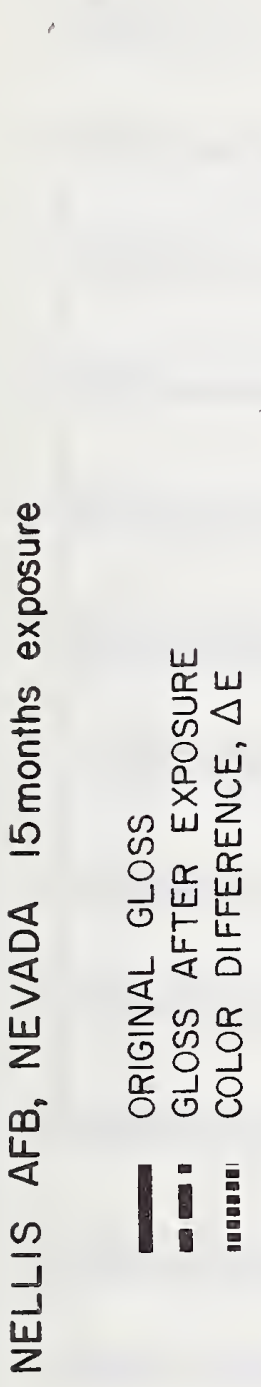

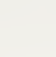
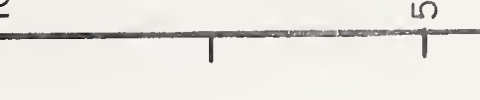


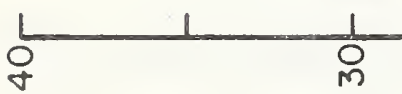


FIGURE $17 \quad$ (B.2)

$\underline{\underline{0}}$

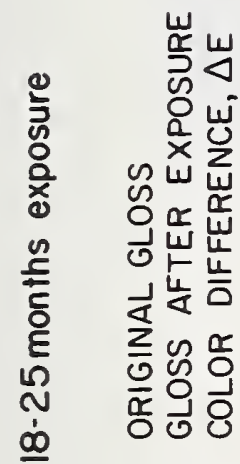
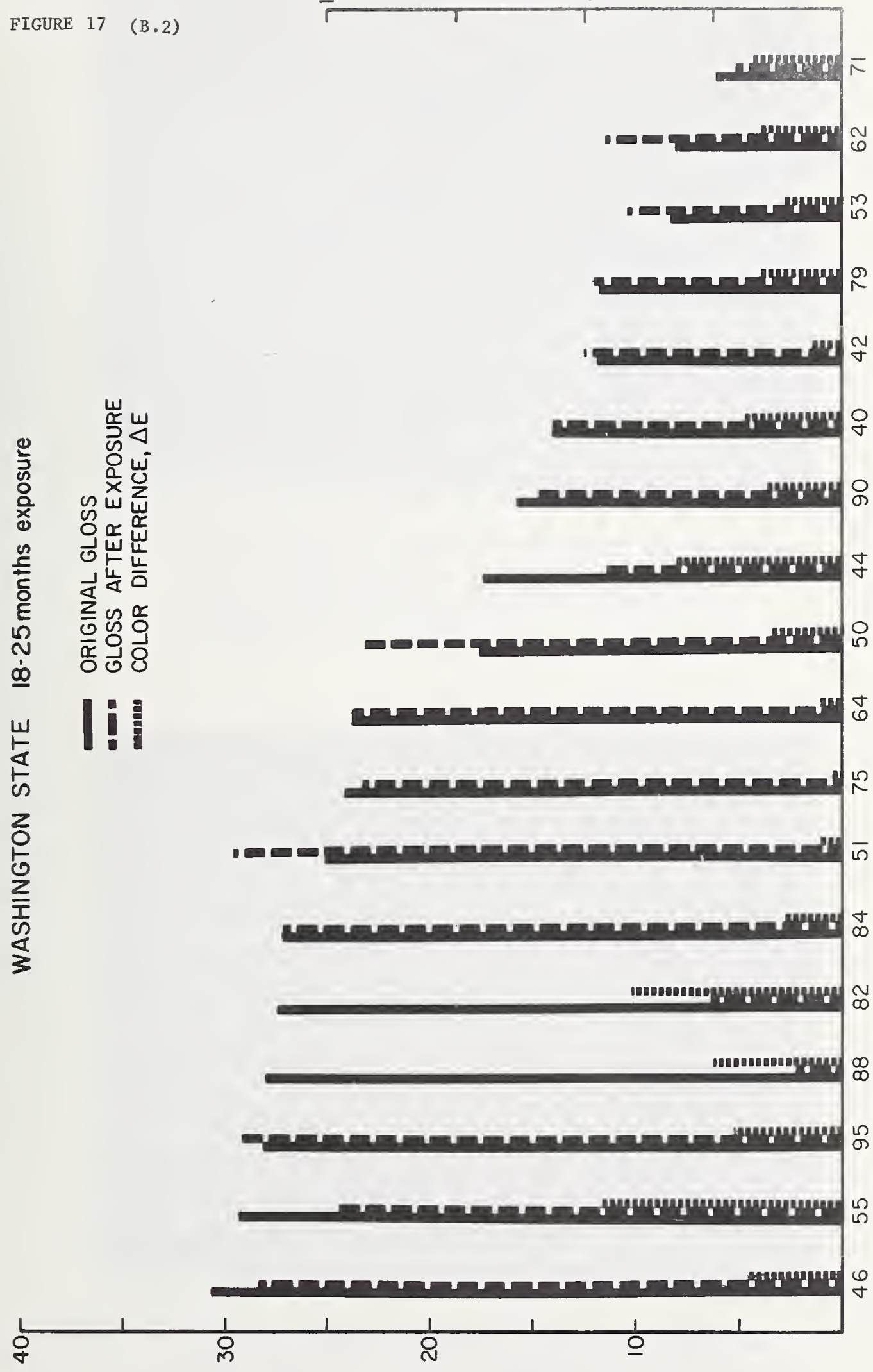



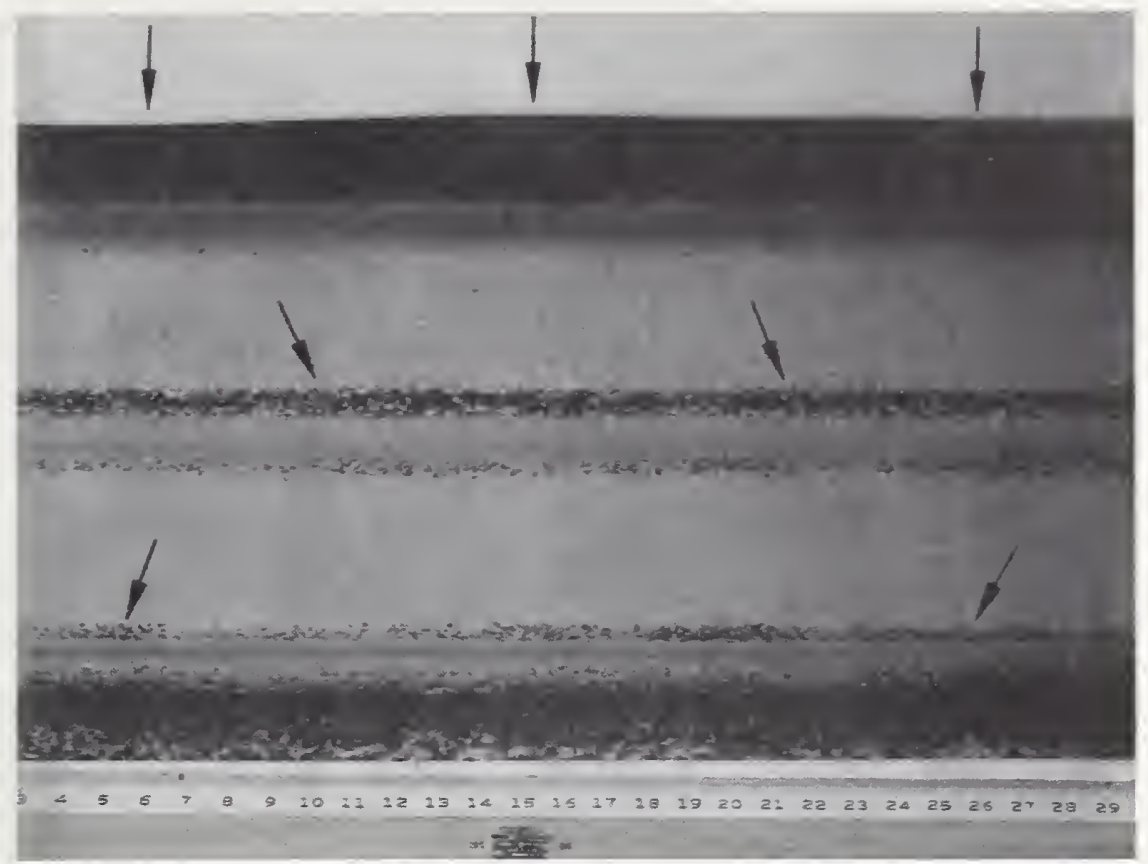

Fig. 20 - Cladding panel exposed 19 months at Cape May, N.J. (seaside site). Arrows indicate areas where substrate is corroded. Scale in centimeters. (B.3)

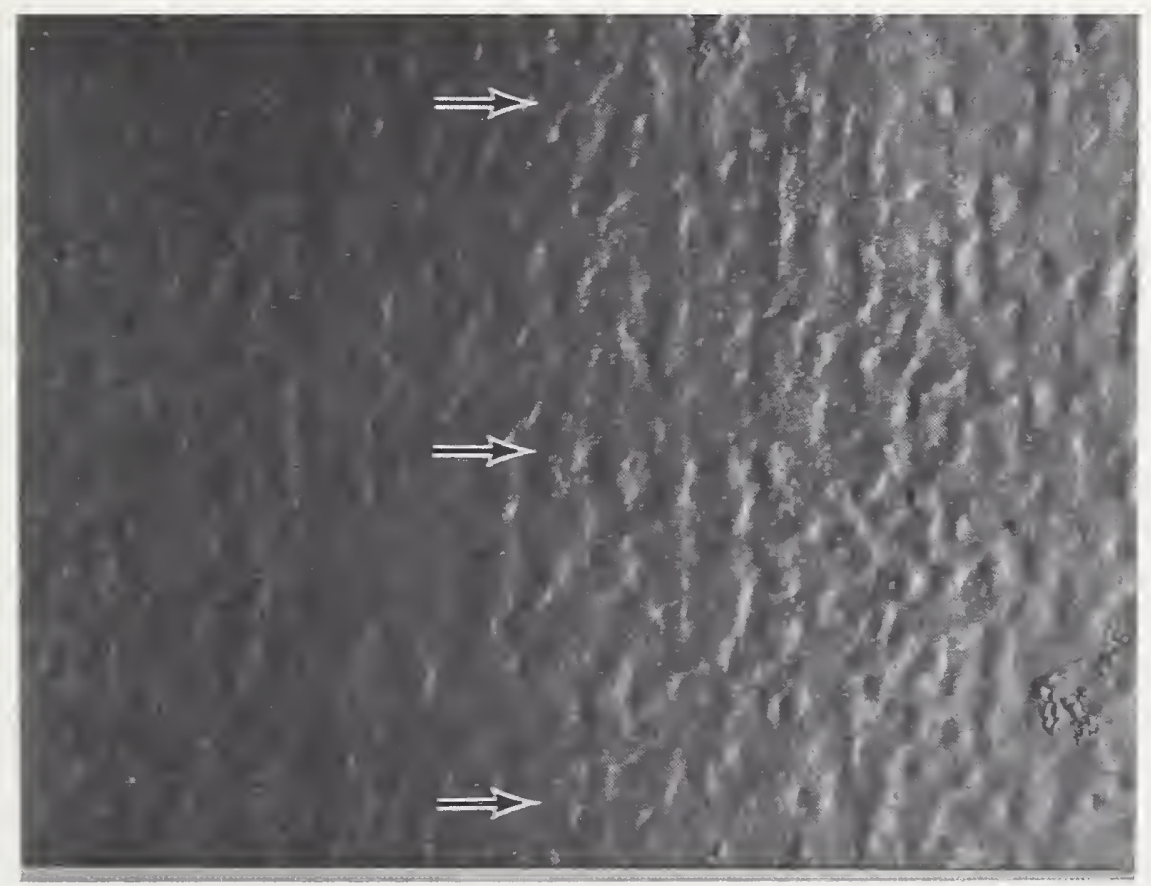

Fig. 21 - Cladding panel exposed 19 months at Cape May, N.J. (seaside site). Panel suface protected by exposure rack is to the right of the arrows. Scale divisions, $0.5 \mathrm{~mm}$. (B.3) 


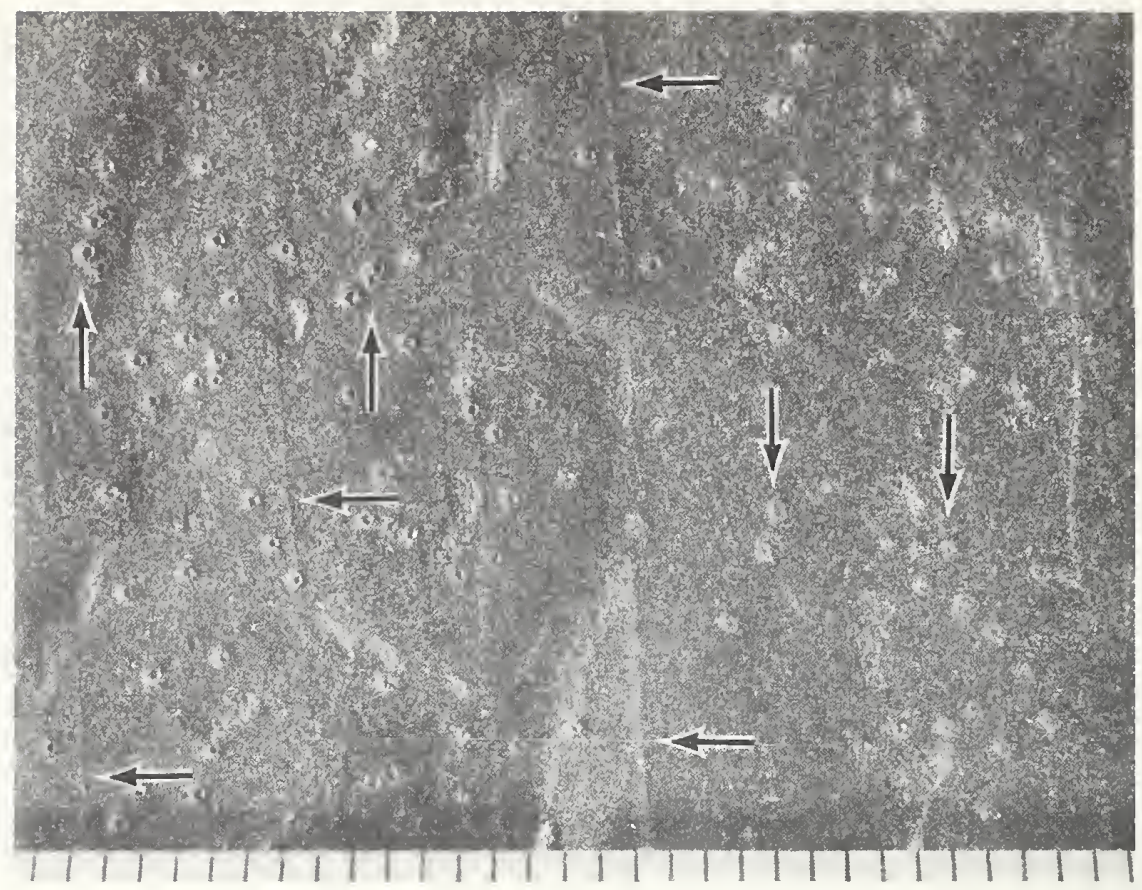

Fig. 22 - Enlargement of pane1 pictured in figure 21; downward arrows indicate unbroken blisters; upward arrows, broken blisters; horizontal arrows, cracks in coating. Scale divisions, $0.5 \mathrm{~mm}$ $0.5 \mathrm{~mm}$. (B.3)

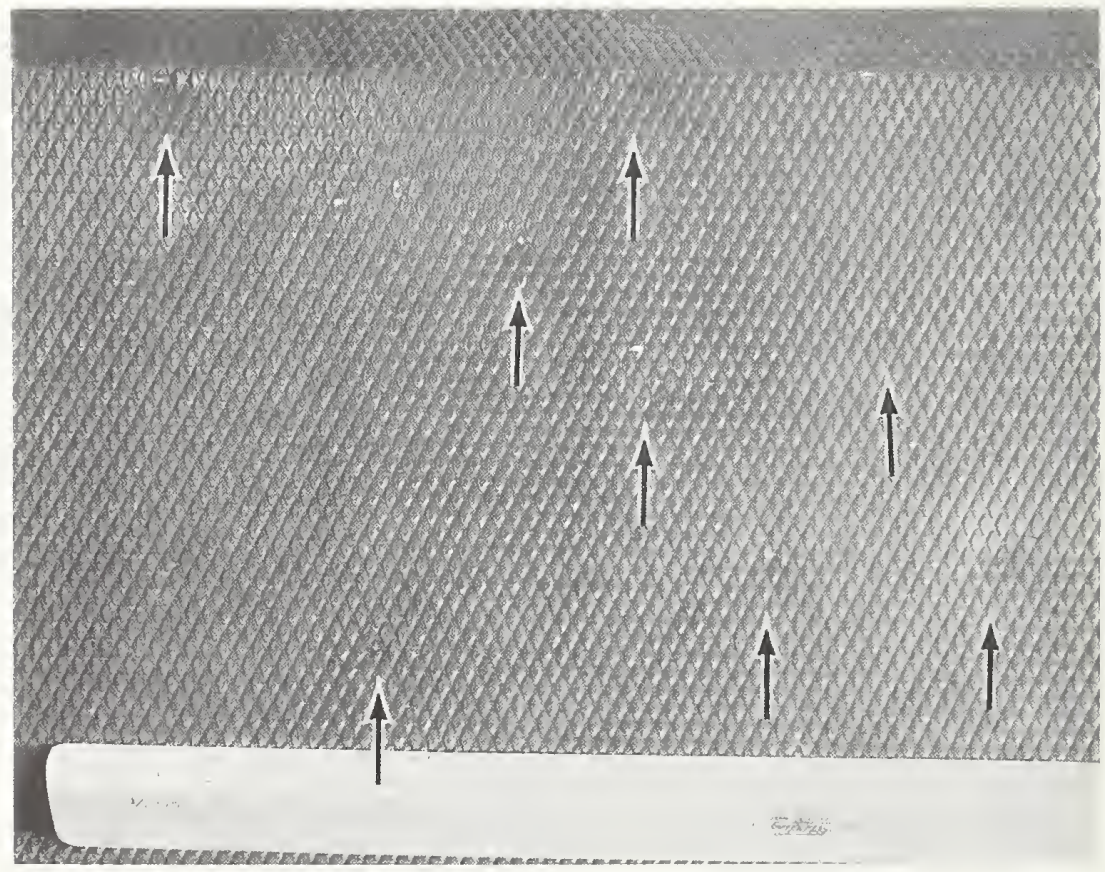

Fig. 23 - Surface depressions (arrows) in light gauge metal substrate cladding after 15 months natural weathering. (B.3) 


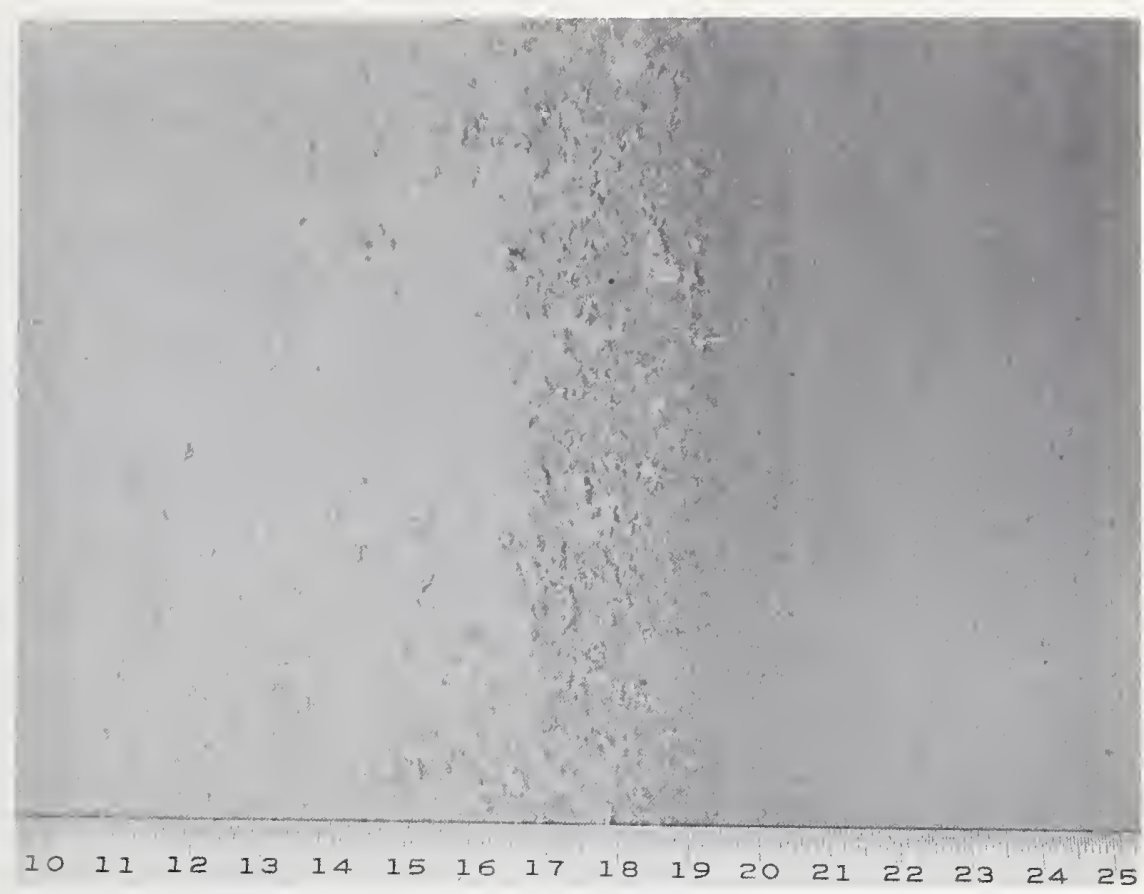

Fig. 24 - Cladding panel exposed 24 months, Gaithersburg, Md. Applied coating deteriorated by not removing protective film from panel. Scale in centimeters. (B.3)

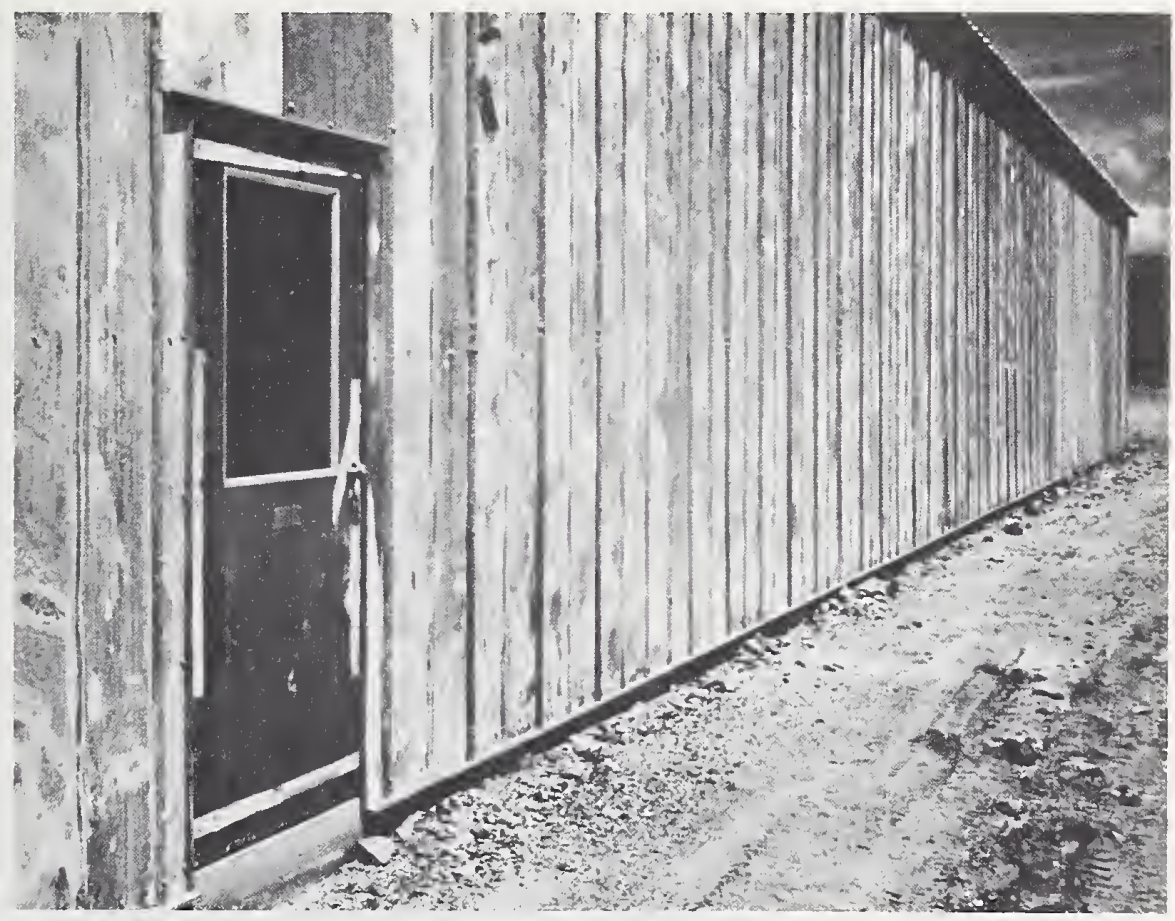

Fig. 25 - Building in Puerto Rico, constructed of non-coated metal cladding. (C.2) 
Fig. 26 - Corrosion of metal substrate where applied coating has been lost from panel (Puerto Rico). (C.2)
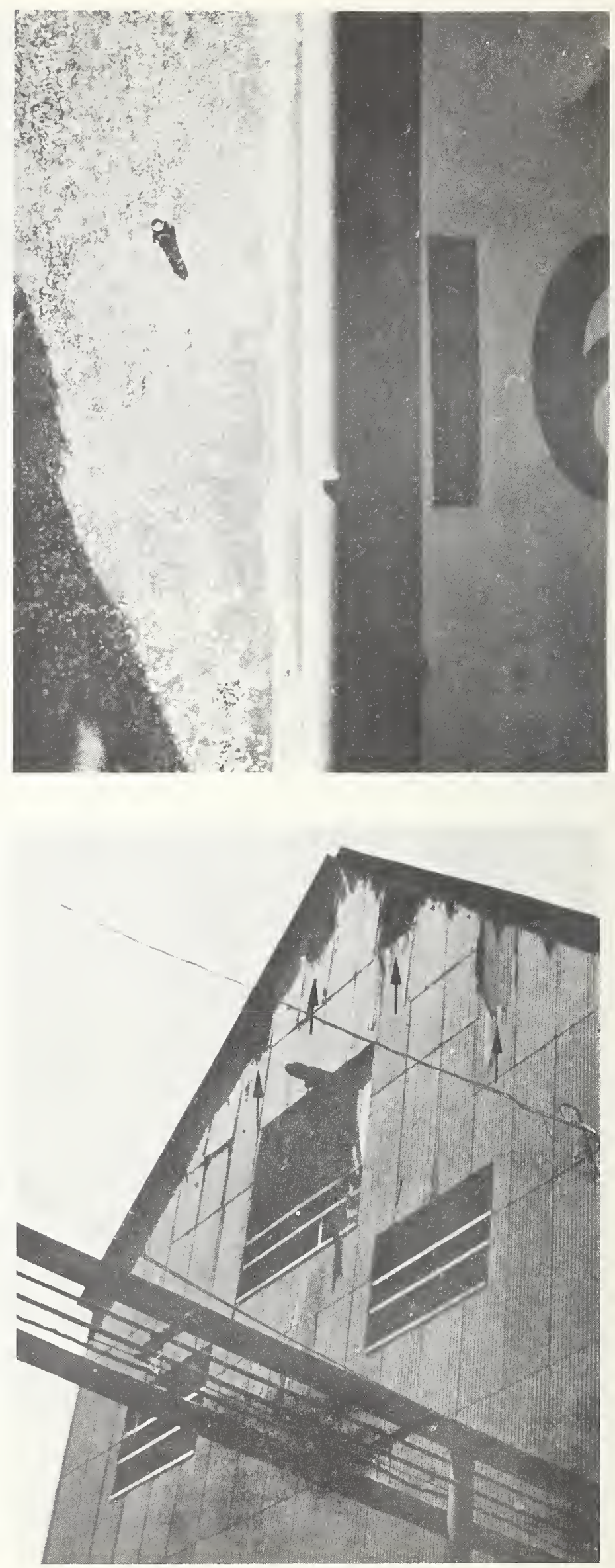

Fig. 27 - Cladding destroyed by corrosive industrial atmosphere (indicated by arrows). (C.2) 


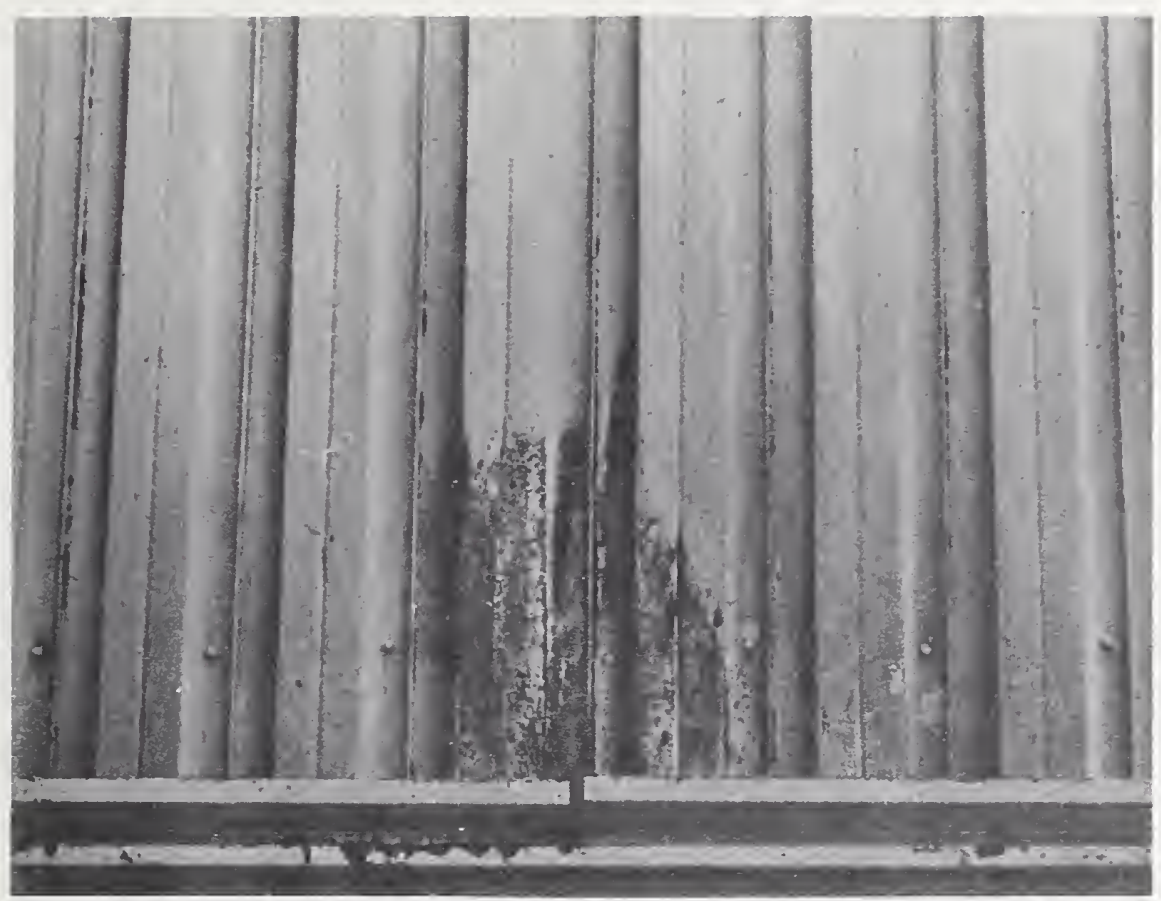

Fig. 28 - Cladding over a heat exchanger exhaust. (C. 2)

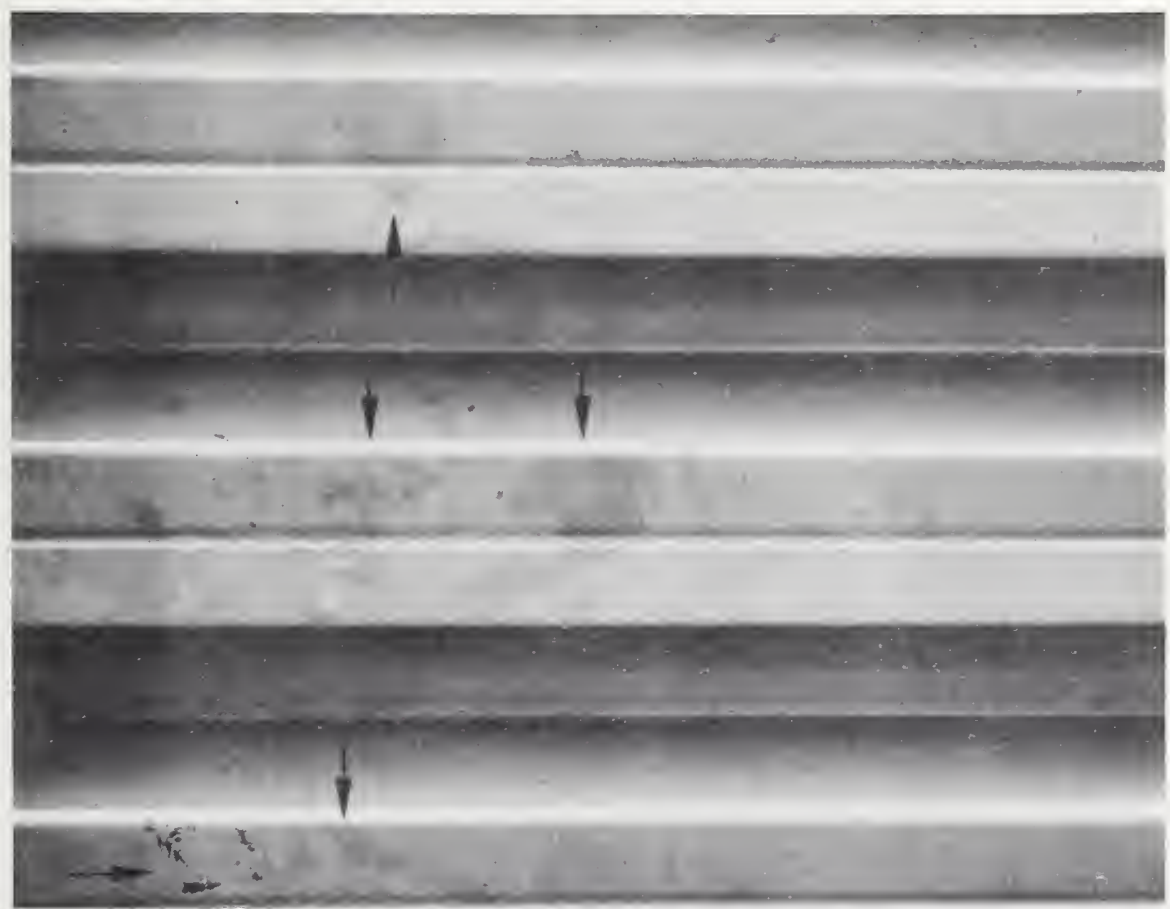

Fig. 29 - Cladding after 5 years near salt water, showing chalking (vertical arrows) and abrasion (horizontal arrow) of the applied coating. (C.2) 


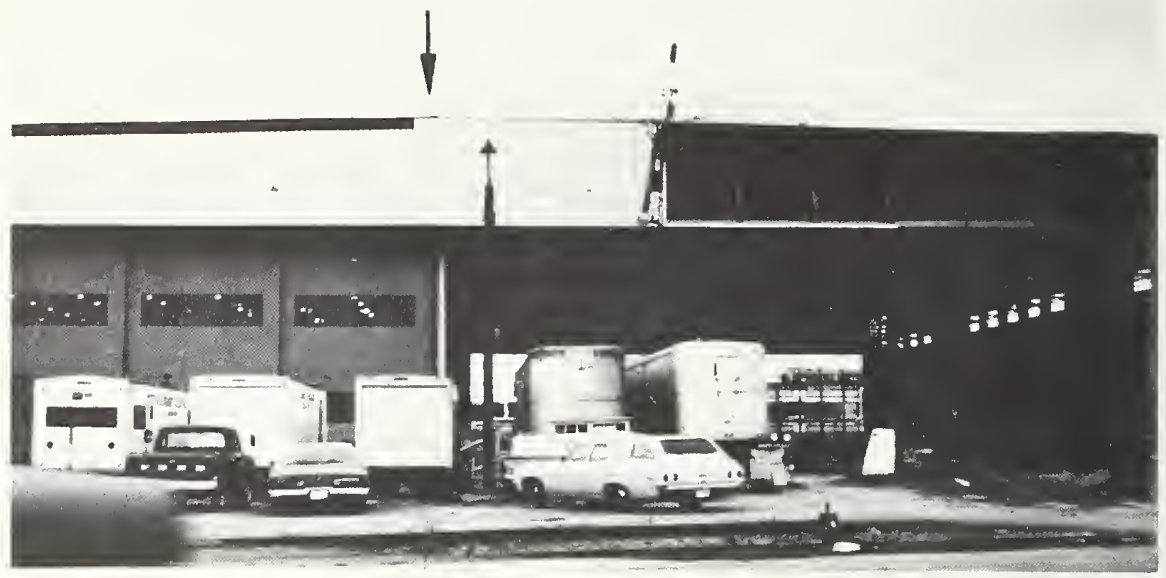

Fig. 30 - New cladding (to the right of the arrow), of same color as original cladding, being added to airplane hanger. (C.2)

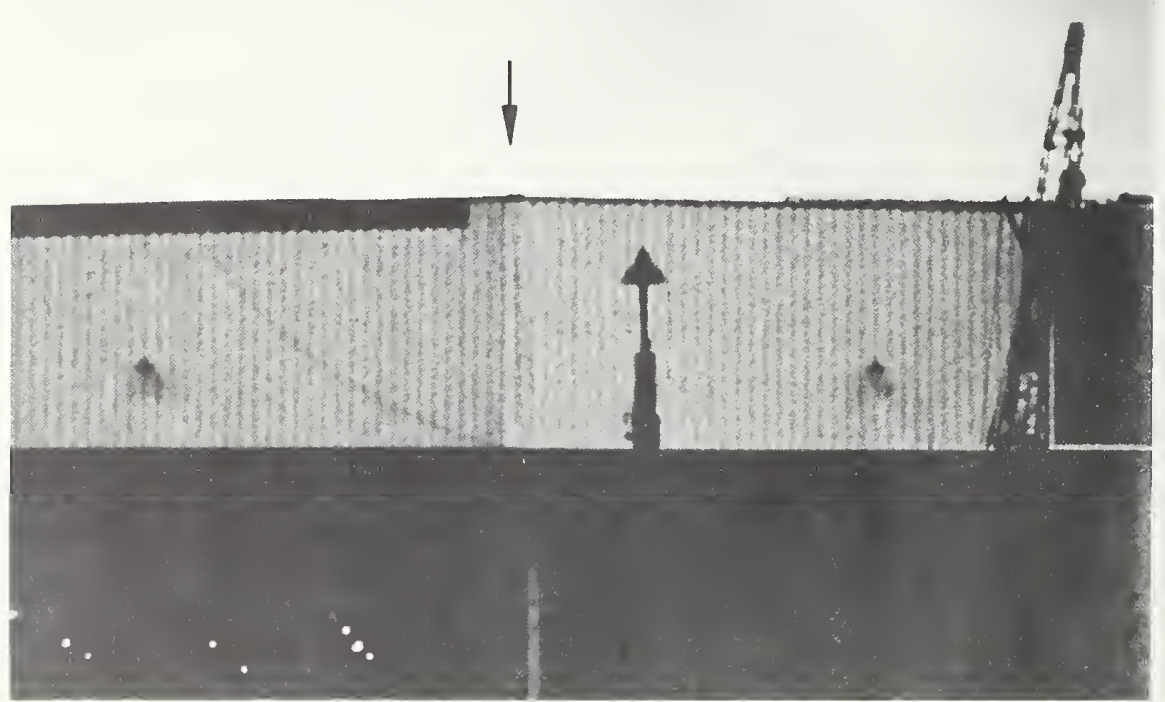

Fig. 31 - Enlargement of figure 30. Color of original cladding (left of arrow) is faded when compared to the identical color in the new cladding (right of arrow. (C.2) 
Fig. 32 - Bu1L1ng wa of Indurtralal cladding with

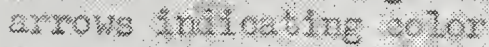
fabe of the applied wouther. $(0,2)$

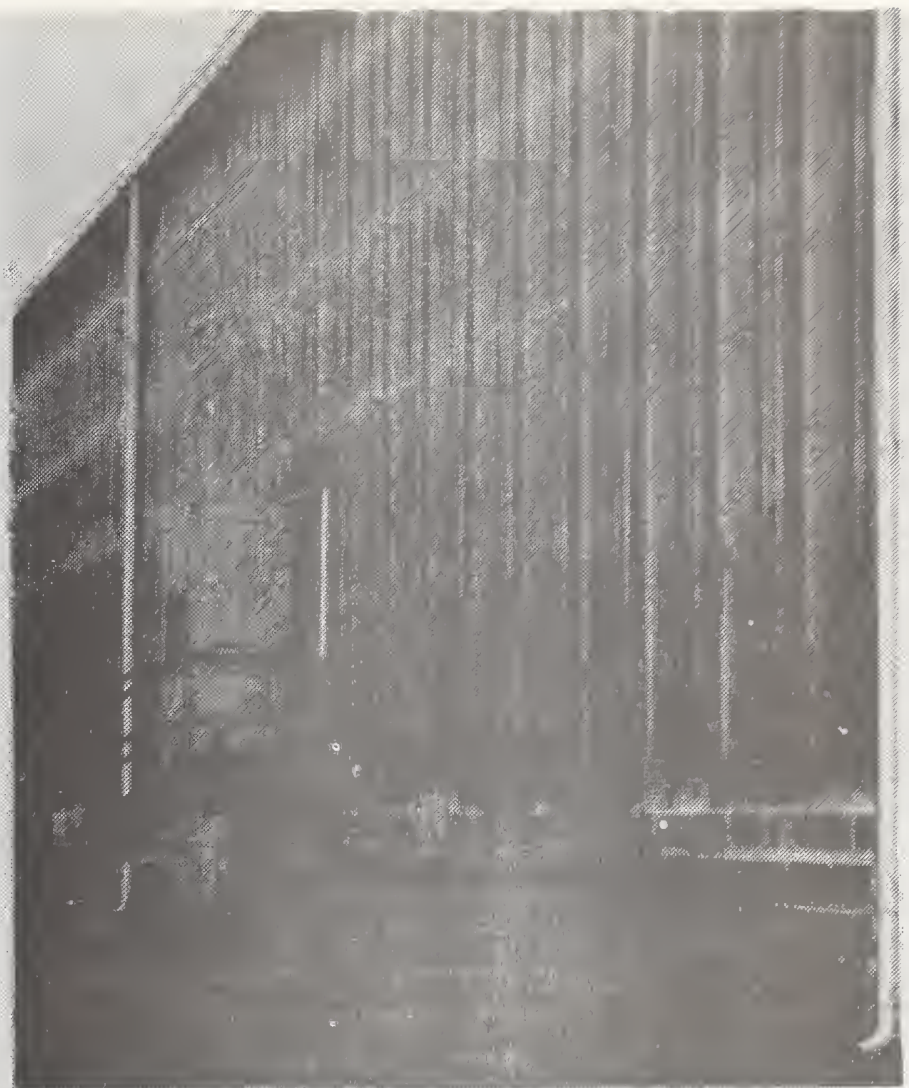

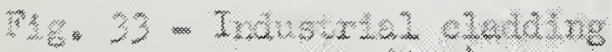

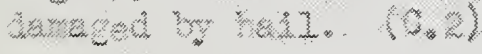

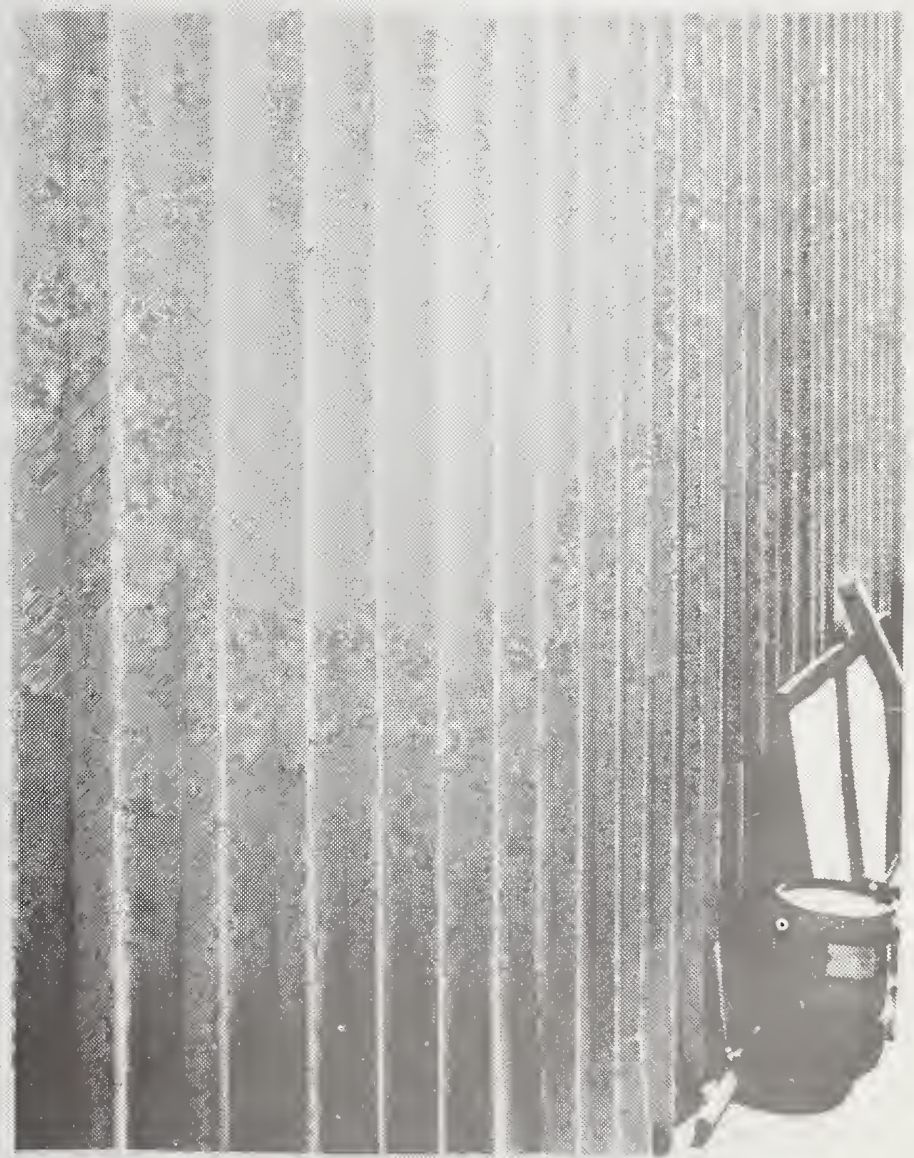





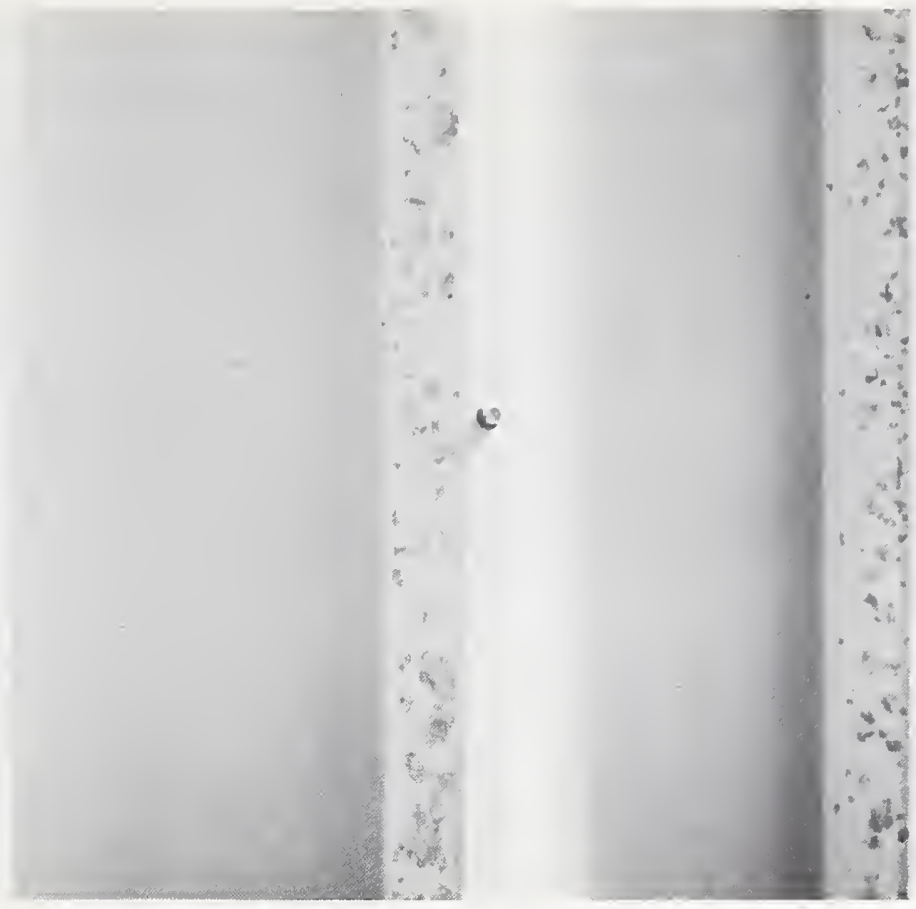

Fig. 34 - Close-up photograph of cladding damage pictured in figure 33, showing substrate exposed by hail impact. (C.2)

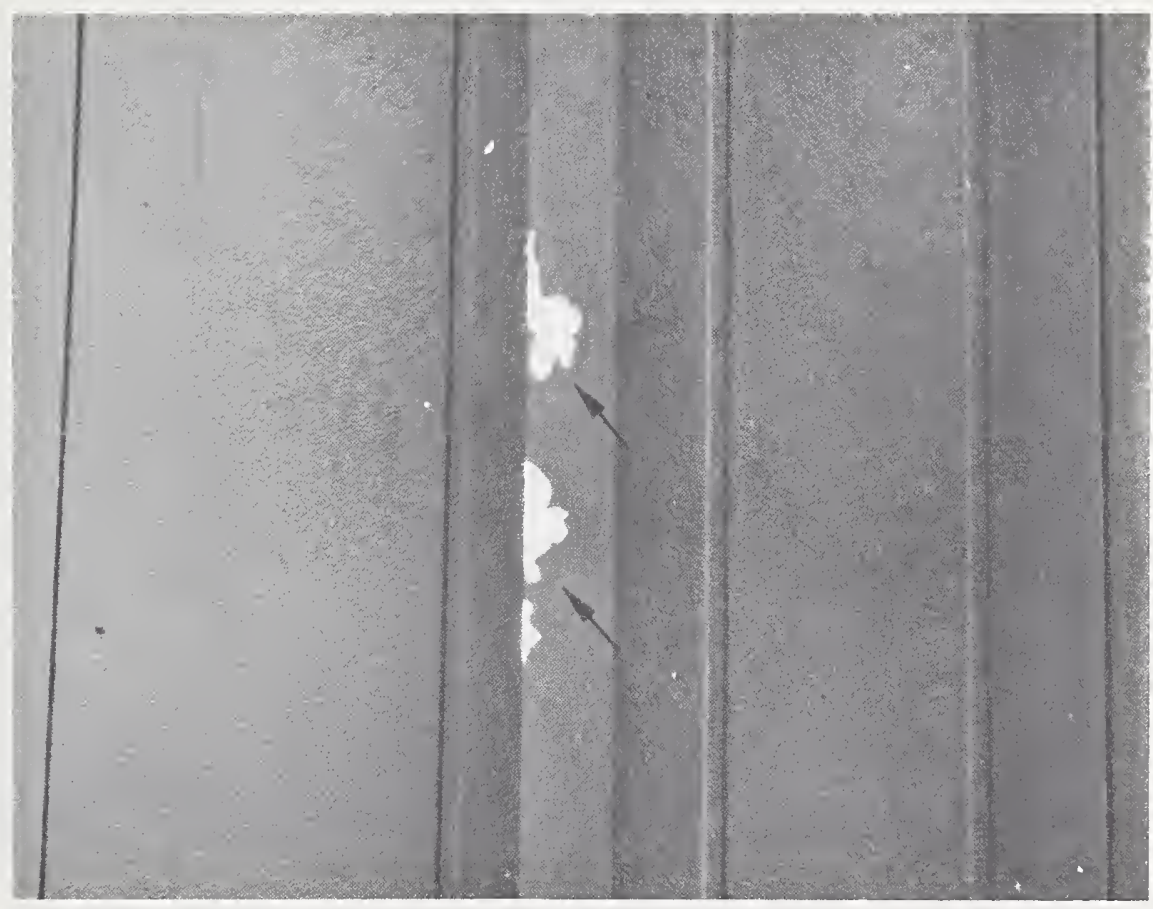

Fig. 35 - Spalling of applied coating (indicated by arrows) due to alleged improper preparation of substrate during factory coating. (E.2) 



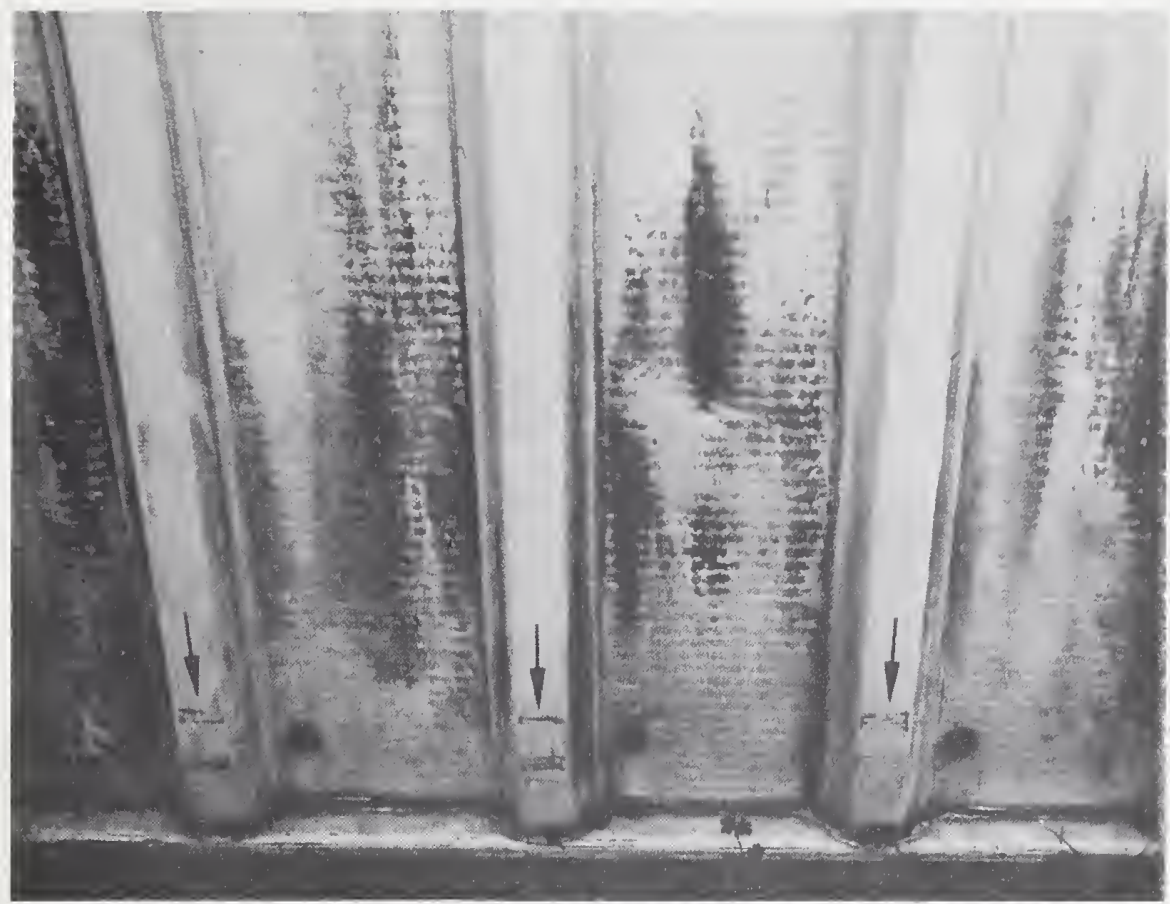

Fig. 36 - Abrasion of panel coating (indicated by arrows) by grass cutting machinery. Dark splotches on panels are from mildew. (E-2)

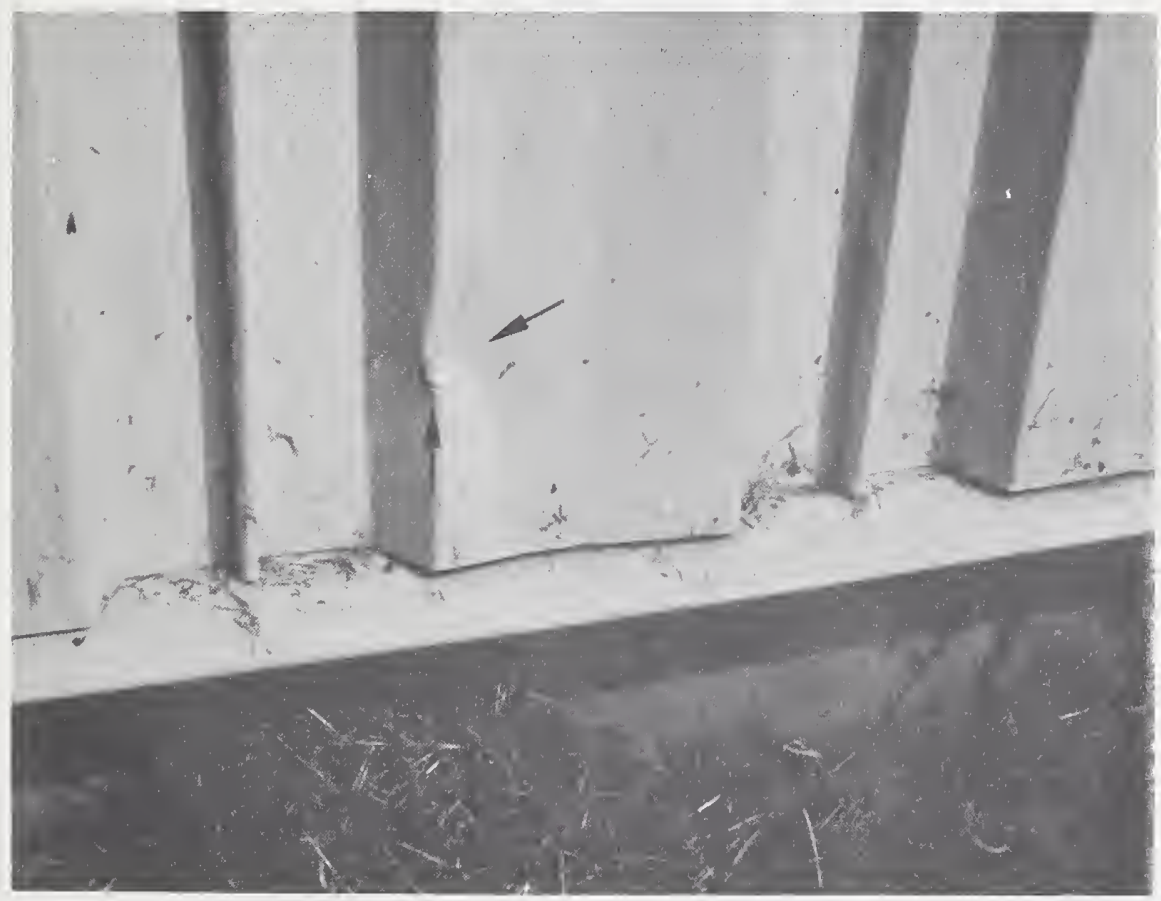

Fig. 37 - Deformation of wall panels (indicated by arrows) from grass cutting machinery. (E.2) 

ag $36-$ Daraged adod!ng next to Lodine conk. (P.2)

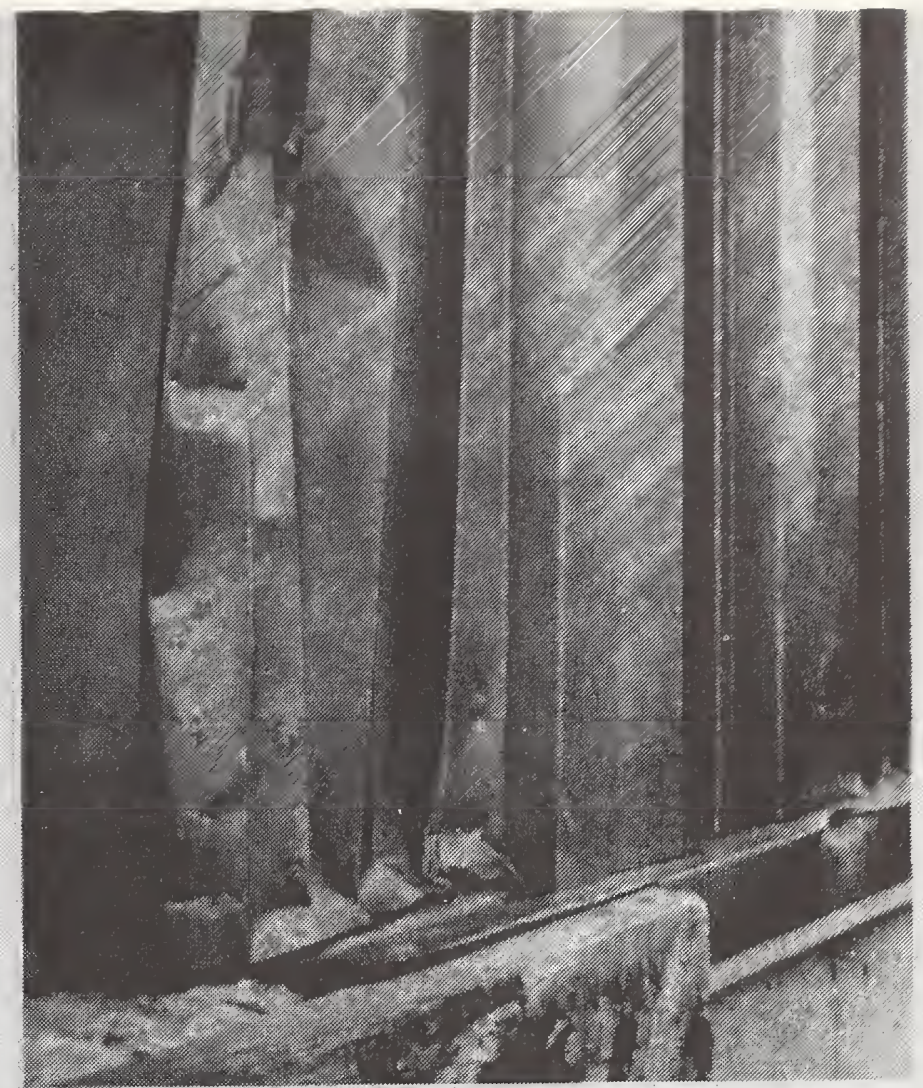

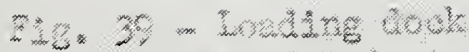

monatructed of smavetrial

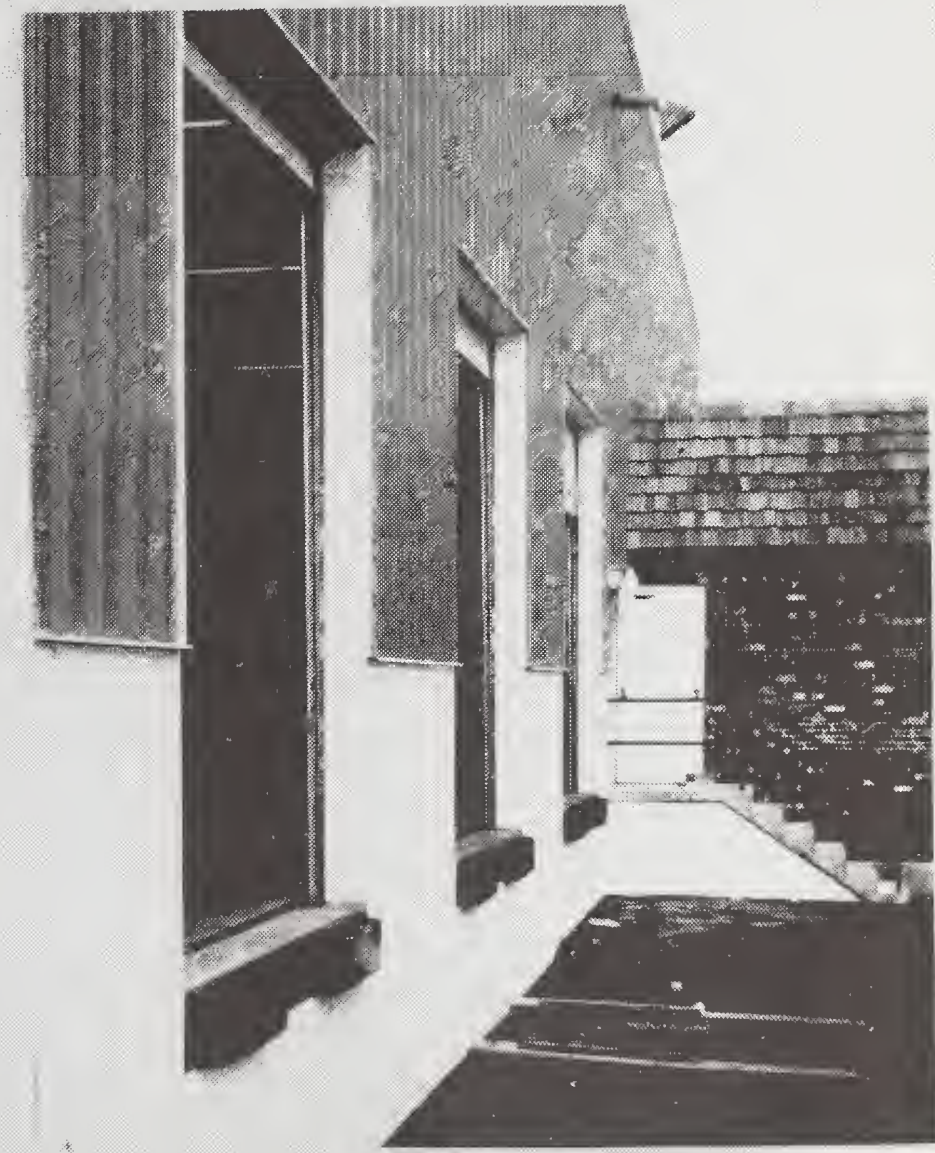

claddang and mosontry. (B.2) 



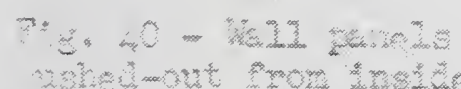

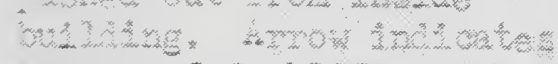

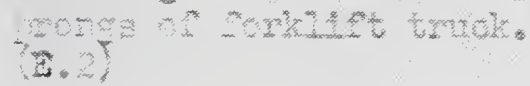
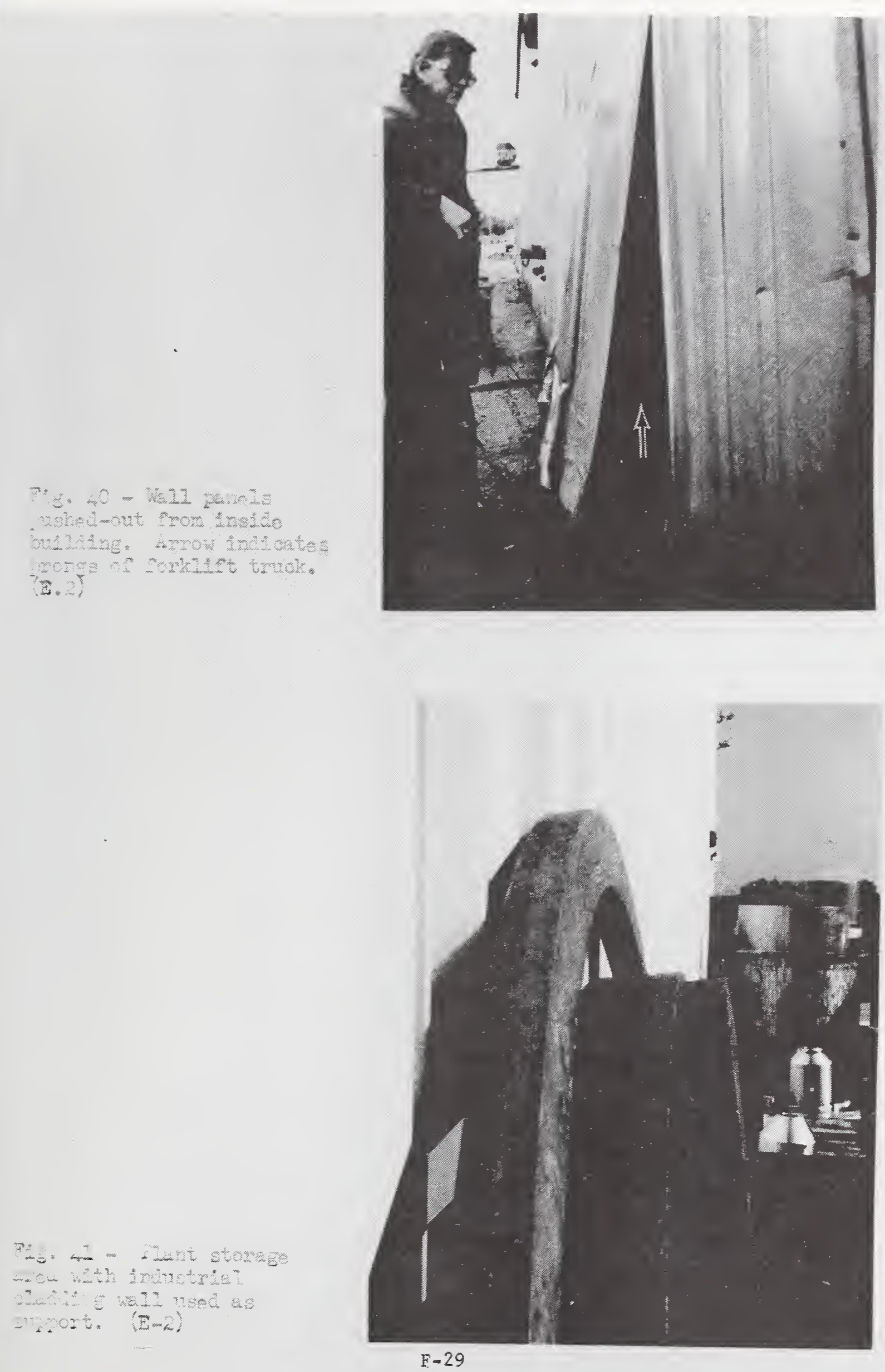



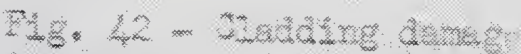
In storage area plotrued $3 \times$ or oure 41. (E.2)
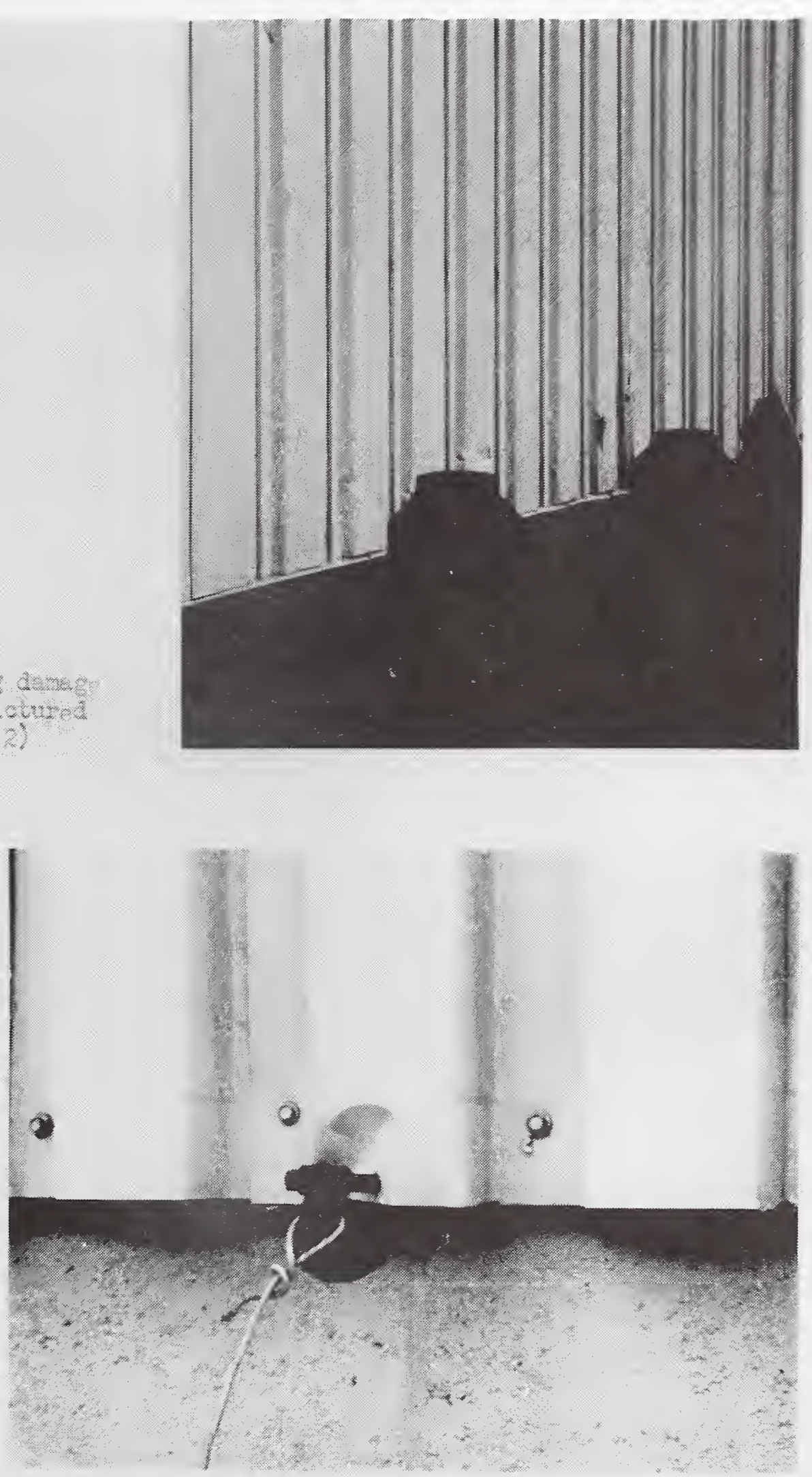

Fig. 43 - Distortion of cladding by attachment of C-clamp used as anchor for door chain. (E.2) 

FORM NBS.114A (1.71)

U.S. DEPT. OF COMM

BIBLIOGRAPHIC DATA

SHEET

1. PUBLICATION OR REPORT NO

NBSIR 73-134

2. Gov't Accession No.

3. Recipient's Accession No.

5. Publication Date

4. TITLE AND SUBTITLE

Performance of Industrial-Type Cladding Materials

6. Performing Organization Code

8. Performing Qrganization

NBSIR 73-134

G.A. Sleater

10. Project/Task/Work Unit No. 4676446

NAT IONAL BUREAU OF STANDARDS

DEP ARTMENT OF COMMERCE

WASHINGTON, D.C. 20234

12. Sponsoring Organization Name and Address

Office of the Chief of Engineers, U.S. Army

Jirectorate of Civiı Englneerıng, U.S. Air Force

Naval Facilities Engineering Command, U.S. Navy
11. Contract/Grant No.

13. Type of Report \& Period Covered

NBS Report 6/69-5/72

14. Sponsoring Agency Code

15. SUPPLEMENTARY NOTES

16. ABSTRACT (A 200-word or less factual summary of most significant information. If document includes a significant bibliography or literature survey, mention it here.)

The main objective of a three year research program in industrial-type cladding systems at the Natioanl Bureau of Standards was to develop a performance specification for such cladding materials. The research program consisted of laboratory and natural weathering tests of commercial cladding specimens, complemented by field inspection of inservice industrial cladding. Only cladding with an aluminum or a galvanized steel substrate, covered with a factory-applied organic coating, was evaluated.

The laboratory testing program included measurement of color and gloss changes consequent to accelerated weathering procedures, and tests for cladding resistance to salt spray, moisture permeation, impact, and abrasion. Exposure of cladding specimens to natural weathering was done at the seven National Bureau of Standards exposure stations. Field inspection tours of in-service cladding were made in the Eastern and Southeastern United States and Puerto Rico.

The criteria to implement the performance specification for industrial cladding were based upon the combined information from test data and field inspection. In addition, the results of cladding exposure to natural weathering were correlated with the test data from cladding exposure to laboratory accelerated weathering procedures. Suggestions for protection of cladding from in-service damage are also given.

17. KEY WORDS (Alphabetical order, separated by semicolons) Accelerated weathering; field

inspection; industrial cladding; natural weathering; organic coatings; performance specification.

18. AVAILABILITY STATEMENT

UNLIMIT ED.

$\chi$ FOR OFFICIAL DISTRIBUTION. DO NOT RELEASE TO NTIS.

19. SECURITY CLASS (THIS REPORT)

UNCL ASSIF IED

20. SECURITY CL ASS ( THIS PAGE)
21. NO. OF PAGES

22. Price 
